\title{
AS ESTRATÉGIAS DE PRECIFICAÇÃO E O DESEMPENHO DAS EMPRESAS
}

\author{
Gabriel Sperandio Milan* \\ gsmilan@ucs.br \\ Evandro Busata Saciloto* \\ evandrsa@hotmail.com \\ Fabiano Larentis* \\ flarenti@ucs.br \\ Deonir De Toni* \\ dtoni2@ucs.br
}

*Universidade de Caxias do Sul - Caxias, RS / Brasil

http://dx.doi.org/10.1590/1413-2311.0982015.57273

Recebido em 23/07/2015

Aprovado em 21/07/2016

Disponibilizado em 31/08/2016

Avaliado pelo sistema "double blind review"

Revista Eletrônica de Administração

Editora-chefe: Aurora Zen

ISSN 1413-2311 (versão "on line")

Editada pela Escola de Administração da Universidade Federal do Rio Grande do Sul.

Periodicidade: Quadrimestral

Sistema requerido: Adobe Acrobat Reader

\section{RESUMO}

O preço é um dos principais aspectos determinantes para a escolha dos produtos pelos compradores. Fatores como maior diferenciação dos produtos, desenvolvimentos tecnológicos e globalização da economia fizerem com que o preço ganhasse importância, pois é um dos elementos chave para alcançar o volume de vendas desejado e por impactar nos lucros e na rentabilidade das empresas. Além disso, as estratégias de precificação são fundamentais para a consolidação de um posicionamento de mercado adequado. Sendo assim, este trabalho analisou as estratégias e os processos de precificação utilizados em 153 empresas afiliadas ao Sindicato das Indústrias Metalúrgicas e de Material Elétrico de Caxias do Sul (RS) (SIMECS), verificando a relação das decisões de preço com o desempenho destas empresas. Como método de pesquisa, foi realizada uma pesquisa quantitativo-descritiva do tipo survey com os responsáveis pelo processo de precificação destas empresas. Para a análise dos resultados, foi empregada a Análise Fatorial e a Análise de Variância (ANOVA). Os principais resultados sugerem que existem diferenças entre as abordagens e as estratégias de preços utilizadas e diferenças de níveis de desempenho apresentados entre os ramos de atuação, bem como em relação ao porte das empresas pesquisadas. Os dados sugerem que empresas que captam melhor o valor percebido pelos clientes, aliado a uma estratégia de preços altos, apresentam um melhor desempenho diante dos seus principais concorrentes. 
Palavras-chave: Preço; Decisões de Preço; Formação de Preços; Estratégias de Preço; Precificação; Desempenho.

\title{
PRICING STRATEGIES AND ENTERPRISES PERFORMANCE
}

\begin{abstract}
The price is one of the main aspects when costumers are choosing products. Factors such as a higher level of differentiation of products, technological developments and globalization of the economy increased the importance of price, because it is a key element in order to reach the sales amount desired as well as for having an impact in the profitability of the companies. Furthermore, the pricing strategies are paramount for a suitable market positioning consolidation. Therefore, this paper has analysed the strategies and the processes of pricing of 153 enterprises that are part of the Sindicato das Indústrias Metalúrgicas e de Material Elétrico of Caxias do Sul (RS) (SIMECS), verifying the relationship between pricing decision make and their performance. As for the research method, a survey was conducted with a quantitative-descriptive approach with the persons responsible for the pricing process in their respective enterprises. The analysis of the results used the Factor Analysis and Analysis of Variance (ANOVA). The main results suggest that there are differences between prices approaches and strategies used and differences in performance levels provided between the activities of branches as well as in relation to the size of the companies surveyed. The data suggest that enterprises that best capture the value perceived by customers, coupled with a high pricing strategy, perform better in front of its main competitors.
\end{abstract}

Keywords: Price; Price Decisions; Price Formation; Price Strategies, Pricing, Performance.

\section{LAS ESTRATEGIAS DE PRECIOS Y EL DESEMPEÑO DE LAS EMPRESAS}

\begin{abstract}
RESUMEN
El precio es uno de los principales aspectos determinantes para la elección de los productos por los compradores. Factores tales como una mayor diferenciación de los productos, los avances tecnológicos y la globalización económica tienen a ver con el aumento de la importancia de precio, ya que es uno de los elementos clave para lograr el volumen deseado de las ventas y el impacto sobre los beneficios y la rentabilidad de las empresas. Además, las estrategias de fijación de precios son fundamentales para la consolidación de un adecuado posicionamiento de mercado. Por lo tanto, este estudio analizó las estrategias y procesos de fijación de precios utilizados en 153 empresas afiliadas a el Sindicato das Indústrias Metalúrgicas e de Material Elétrico de Caxias do Sul (RS) (SIMECS), con la intención de comprobar la relación de las decisiones de fijación de precios con el desempeño de estas empresas. Como método de investigación, se llevó a cabo una investigación cuantitativa descriptiva con los responsables de la fijación de precios de estas empresas. Para analizar los resultados, se utilizó el Análisis Factorial y el Análisis de la Varianza (ANOVA). Los principales resultados indican que existen diferencias entre los enfoques y estrategias de precios utilizadas y diferencias en los niveles de rendimiento previstos entre las ramas de
\end{abstract}




\section{Gabriel Sperandio Milan, Evandro Busata Saciloto, Fabiano Larentis \& Deonir De Toni}

actividad, así como en relación con el tamaño de las empresas encuestadas. Los datos sugieren que las empresas que mejor captan el valor percibido por los clientes, junto con una estrategia de alto precio, tienen un mejor desempeño frente a sus principales competidores.

Palabras clave: Precios; Las Decisiones de Precios; Fijación de Precios; Estrategias de Precios; Pricing; Desempeño.

\section{INTRODUÇÃO}

Na década de 70, Oxenfeldt (1973) já defendia a criação de procedimentos sistemáticos para o desenvolvimento de estratégias de preços (precificação), estruturando as decisões de preços. Como os mercados mudam e as empresas alteram seus respectivos planos de marketing para aproveitar oportunidades e minimizar ameaças, gerando lucro e rentabilidade, dentre outras decisões, isto obriga aos gestores a adotarem estratégias e decisões de preços mais adequadas (LANCIONI; SCHAU; SMITH, 2005).

Entretanto, muitas empresas determinam seus preços com base na intuição, em paradigmas vigentes e na experiência de mercado dos seus gestores, não levando em conta estudos mais aprofundados e inerentes a este processo (DOLAN; SIMON, 1998). Além disso, há um conflito permanente entre os gestores incumbidos de aferir os custos, geralmente profissionais das áreas de finanças e contabilidade (ou controladoria), e os gestores incumbidos de satisfazer os clientes, profissionais das áreas de marketing e/ou de vendas. Este conflito entre estas áreas das organizações, com seus respectivos pontos de vista, desgasta o diálogo, não potencializa os recursos e os possíveis ganhos das empresas e leva às decisões relativas aos preços a se constituírem em acordos imperfeitos (NAGLE; HOLDEN, 2003).

O número de ofertas aumenta cada vez mais com competidores qualificados e com os novos entrantes, o que faz com que o preço represente um dos elementos mais importantes para a sustentabilidade de uma empresa a curto, médio e longo prazo (NICHELE; MILAN, 2006). Vale destacar que o cenário de mercado requer empresas competitivas, com políticas e estratégias de preços assertivas, exigindo planejamento e gerenciamento adequados para operarem com altos custos e riscos inerentes ao processo de comercialização, seja em âmbito nacional, seja em âmbito internacional (RAMOS et al., 2005).

Logicamente, os estudos sob as teorias inerentes aos custos evoluíram com o objetivo de explicar a rigidez de preços, no que se refere ao porquê as empresas alteram seus preços com menos frequência do que a Teoria Econômica poderia prever. Estudos sob a perspectiva REAd | Porto Alegre - Edição 84 - N 2 - Maio / Agosto 2016 - p. 419 - 452 
de um determinado processo de decisão iniciam a partir da tentativa de elaboração de uma teoria sobre o comportamento dos gestores, a qual vê a empresa como uma coalizão de stakeholders, que negociam sobre os seus objetivos, o que inclui as práticas de preços, que requerem recursos tais como informações, habilidade e conhecimento (DUTTA; ZBARACKI; BERGEN, 2003). Por sua vez, estudos que se originam sob a perspectiva de marketing abordam a importância do preço no mix de marketing, emergindo estudos relacionados aos objetivos de preços dominantes (AVLONITIS; INDOUNAS, 2005) e outros estudos que examinam a viabilidade das estratégias de preço e seus determinantes (INGENBLEEK, 2007).

Inclusive, os estudos sobre preço variam consideravelmente entre indústrias (setores), países e tipos de clientes e/ou consumidores (compradores), dependendo de suas características. Porém, as abordagens entre os pesquisadores podem ser classificadas, basicamente, em três grupos: preço baseado em custos, preço baseado na concorrência e preço baseado no valor para o cliente (HINTERHUBER, 2008). Talvez por isso Ingenbleek et al. (2003) partem do pressuposto de que estes parâmetros (ou abordagens) podem ser utilizadas concomitantemente, pois não são perspectivas mutuamente excludentes, mas sim até mesmo complementares.

$\mathrm{O}$ aspecto positivo é que o preço tem sido reconhecido como um elemento importante para a maximização do lucro e da rentabilidade das empresas (HINTERHUBER, 2004; NICHELE; MILAN, 2006; SOON, 2011; LARENTIS et al., 2013). Consoante isso, os gestores devem entender o contexto da precificação em relação ao contexto mercadológico em que a empresa está inserida, principalmente a percepção de valor para o comprador e o preço praticado no mercado e sua influência no desempenho do negócio. Porém, é vital que os gestores também verifiquem as interfaces e implicações dos métodos e sistemas de aferição de custos no que diz respeito à estratégia de precificação adotada (MILAN et al., 2013).

Tendo em vista que o preço é um elemento importante e geralmente negligenciado no contexto do marketing como um todo, é oportuno ressaltar que, mais especificamente ao contexto industrial, em média, um aumento de preços na magnitude de $1 \%$ pode levar a uma melhoria de cerca de 11\% nos lucros (BAKER; MARN; ZAWADA, 2010). Os preços têm um impacto muito maior do que outras alternativas inerentes ao mercado ou aos demais aspectos financeiros (HINTERHUBER, 2004). Ou seja, estabelecer uma política e estratégia de preços equivocada pode prejudicar a atividade e o desempenho das empresas (KOHLI; SURI, 2011; LIOZU et al. 2012; INGENBLEEK; FRAMBACH; VERHALLEN, 2013; LIOZU; HINTERHUBER, 2013). Para Liozu e Hinterhuber (2012), há a necessidade de mais 


\section{Gabriel Sperandio Milan, Evandro Busata Saciloto, Fabiano Larentis \& Deonir De Toni}

pesquisas sobre as práticas de preços, pois somente menos de $2 \%$ de todos os artigos publicados nos principais periódicos de marketing se concentram em preços. A temática também é defendida pelo MSI - Marketing Science Institute, colocando-a como prioridade na agenda de pesquisas para o triênio 2014-2016 (MSI, 2015).

Por conseguinte, o presente estudo assumiu a seguinte questão central de pesquisa a ser respondida: Qual a relação das estratégias de precificação adotadas pelas empresas e o seu desempenho? Para tanto, foram definidos os seguintes objetivos de pesquisa: (i) identificar os fatores relacionados à formação de preços nas empresas analisadas; (ii) verificar quais são os fatores relacionados às estratégias de precificação das empresas; e (iii) analisar o desempenho das empresas em relação à concorrência. Para tanto, foi implementada uma pesquisa quantitativo-descritiva, por meio de uma survey, junto aos responsáveis pelo processo de precificação de 153 empresas dos ramos metalmecânico, automotivo e eletroeletrônico, localizadas em uma cidade da Serra Gaúcha, sendo empregadas, na análise dos resultados, a Análise Fatorial e a Análise de Variância (ANOVA).

Em relação à estrutura do artigo, inicialmente, apresentou-se uma contextualização da temática pesquisada, bem como a questão central de pesquisa e os seus objetivos (geral e específicos). Nas seções seguintes, foi abordado o referencial teórico necessário à fundamentação dos aspectos contemplados no estudo; o método de pesquisa, com as respectivas técnicas e procedimentos adotados no processo de coleta, análise e interpretação dos resultados; a apresentação dos resultados propriamente dita; e, por fim, foram tecidas algumas considerações finais.

\section{REFERENCIAL TEÓRICO}

\section{1 Definição de Preços e a Decisão dos Objetivos de Preço}

Dentre os conceitos de preço encontrados na literatura existem vários que não são conflitantes, mas complementares entre si. Para Churchill Jr. e Peter (2013), o preço é conceituado como a quantidade de dinheiro que deve ser dada em troca para se adquirir a propriedade ou o direito ao consumo ou à utilização de um produto ou serviço. O preço estabelece uma base para culminar uma troca entre as partes envolvidas, o que pode representar uma perspectiva para os compradores e outra para os vendedores. Desta forma, o

REAd | Porto Alegre - Edição 84 - N 2 - Maio / Agosto 2016 - p. 419 - 452 
preço se torna um fator de julgamento de acordo com a percepção do potencial de satisfação gerado por um produto e/ou serviço (INGENBLEEK; FRAMBACH; VERHALLEN, 2013). O preço não é um conceito único, mas multidimensional com diferentes significados e aplicações para o partícipes de uma negociação (HOLLENSEN, 2006; SAXENA, 2009).

As decisões de preço de uma empresa são influenciadas por fatores organizacionais, internos, que incluem os objetivos de marketing da empresa, as estratégias do mix de marketing, os custos e a organização como um todo, enquanto os fatores ambientais externos incluem a natureza do mercado e da demanda, a concorrência e outros elementos ambientais (INGENBLEEK;VANDERLANS, 2013). Nãoexiste, portanto, uma única forma de solucionar e organizar a precificação. Antes de definir o preço, a empresa deve decidir qual será sua estratégia para a sua oferta, e quais serão os objetivos a serem alcançados, pois quanto mais claros forem mais fácil será o estabelecimento de preços (HINTERHUBER;LIOZU, 2012;2014).

Então, para desenvolver um planejamento de preços requer que uma empresa se comprometa com um conjunto de objetivos, que podem ser expressos em termos de variações percentuais de aumento no volume de negócios (faturamento, vendas), de participação de mercado (market share), de margens de contribuição, de lucro, de rentabilidade e de retorno sobre investimentos (HINTERHUBER, 2004; LANCIONI, 2005; KOHLI; SURI, 2011).

Os poucos estudos relacionados aos objetivos de preços, evidenciam que os objetivos quantitativos tendem a ser considerados como mais relevantes, com ênfase particular nos lucros de curto prazo (DIAMANTOPOULOS, 1991; AVLONITIS; INDOUNAS, 2005). Todavia, a determinação dos objetivos de preço é o ponto de partida para as estratégias de preço. Os objetivos da precificação ditam o resultado direto da implementação das estratégias global da empresa e de precificação, que deverão ser convergentes (SHIPLEY; JOBBER, 2001).

Segundo Hinterhuber (2004), o objetivo de preços pode variar conforme o tipo de produto e/ou serviço comercializado, e ao longo do tempo, mesmo dentro de uma empresa ou unidade de negócios, em âmbito regional, nacional ou internacional, se for o caso. Embora os objetivos de preço se configure como um processo prévio para se determinar uma estratégia de preço, a qual será uma base para decisões lucrativas e rentáveis a médio e a longo prazo, as estratégias de preço são sempre específicas ao contexto em análise e, deste modo, os gestores podem ser forçados a modificá-las, ou seja, dependem das condições do mercado, do comportamento de compradores e competidores e dos objetivos de marketing da empresa.

REAd | Porto Alegre - Edição 84 - N 2 - Maio / Agosto 2016 - p. 419 - 452 


\section{Gabriel Sperandio Milan, Evandro Busata Saciloto, Fabiano Larentis \& Deonir De Toni}

Como objetivos de preço, podem ser considerados: maximização das vendas, participação de mercado, liquidez e de lucros e de rentabilidade, cobertura dos custos, retorno sobre ativos e investimentos, estabilidade do volume de negócios no mercado e níveis de preços praticados, determinação de preços justos aos clientes, manutenção dos atuais clientes, sobrevivência da empresa e desencorajamento de novos entrantes, dentre outros (DIAMANTOPOULOS, 1991; AVLONITIS; INDOUNAS, 2005; STIVING, 2013).

\subsection{Estratégias de Preço (ou de Precificação) e Abordagens para a Fixação de Preços}

A estratégia de preços fornece um meio pelo qual a empresa pode atingir seu(s) objetivo(s) de preço (TELLIS, 1986; NOBLE; GRUCA, 1999; TORRES; MARTINS, 2006). Sendo assim, a estratégia de preços deve ser formulada para depois ser implementada, podendo ser definida como os direcionamentos que as empresas tem em relação aos seus preços, em seu mercado de atuação (INGENBLEEK; VAN DER LANS, 2013). A estratégia de preços é uma escolha fundamentada em um conjunto de preços alternativos (ou mesmo em uma tabela de preços), que visam à maximização do lucro e a rentabilidade dentro de um período de planejamento em resposta a um determinado cenário em análise (TELLIS, 1986). A diferença entre a fixação convencional de preços e a precificação estratégica consiste em reagir às condições de mercado ou gerenciá-las proativamente, exercendo o nível de preços mais lucrativo e rentável pela geração de mais valor aos clientes e à empresa, sem a obrigatoriedade de aumentar o volume de vendas (faturamento) da empresa (NAGLE; HOLDEN, 2003).

A Figura 1, de forma ilustrativa, traz as nove estratégias preço-qualidade possíveis, considerando, como referência, os níveis de qualidade do produto e/ou serviço (alta, média e baixa) em comparação aos níveis de preço (alto, médio e baixo).

\section{Figura 1 - Estratégias preço-qualidade}

\begin{tabular}{|c|c|c|c|c|}
\hline \multirow{5}{*}{ 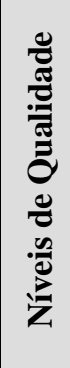 } & \multicolumn{4}{|c|}{ Níveis de Preço Praticado } \\
\hline & Níveis & Alto & Médio & Baixo \\
\hline & Alta & $\begin{array}{l}\text { 1. Estratégia } \\
\text { Premium }\end{array}$ & $\begin{array}{l}\text { 2. Estratégia } \\
\text { de Alto Valor }\end{array}$ & $\begin{array}{c}\text { 3. Estratégia } \\
\text { de Valor Supremo }\end{array}$ \\
\hline & Média & $\begin{array}{l}\text { 4. Estratégia } \\
\text { de Preço Alto }\end{array}$ & $\begin{array}{c}\text { 5. Estratégia } \\
\text { de Preço Médio }\end{array}$ & $\begin{array}{c}\text { 6. Estratégia } \\
\text { de Valor Médio }\end{array}$ \\
\hline & Baixa & $\begin{array}{l}\text { 7. Estratégia } \\
\text { de Desconto }\end{array}$ & $\begin{array}{c}\text { 8. Estratégia } \\
\text { de Falsa Economia }\end{array}$ & $\begin{array}{l}\text { 9. Estratégia } \\
\text { de Economia }\end{array}$ \\
\hline
\end{tabular}

REAd | Porto Alegre - Edição 84 - Nº 2 - Maio / Agosto 2016 - p. 419 - 452 
AS ESTRATÉGIAS DE PRECIFICAÇÃO E O DESEMPENHO DAS EMPRESAS

Fonte: Adaptada de Kotler (2000).

Para ampliar a compreensão acerca de outras estratégias de preço, segue a Figura 2.

Figura 2 - Outras estratégias de preço

\begin{tabular}{|c|c|c|c|}
\hline Situações & Estratégias & Descrição & Contextualização da Estratégia \\
\hline \multirow{3}{*}{ 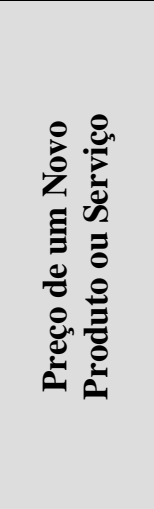 } & Desnatamento & $\begin{array}{l}\text { Alto preço inicial, } \\
\text { reduzido de forma } \\
\text { sistemática, gradativa }\end{array}$ & $\begin{array}{l}\text { Alta diferenciação da oferta (produto e/ou } \\
\text { serviço), demanda de mercado inelástica, } \\
\text { alta utilização da capacidade e desvantagem } \\
\text { de custos em função da escala }\end{array}$ \\
\hline & Penetração & $\begin{array}{l}\text { Preço inicial baixo para } \\
\text { acelerar a adoção do } \\
\text { produto ou do serviço }\end{array}$ & $\begin{array}{l}\text { Baixa diferenciação da oferta (produto e/ou } \\
\text { serviço) no mercado, vantagem de custo } \\
\text { em função da escala, baixa utilização da } \\
\text { capacidade e demanda de mercado elástica }\end{array}$ \\
\hline & $\begin{array}{l}\text { Curva de } \\
\text { Experiência }\end{array}$ & $\begin{array}{l}\text { Preço baixo para } \\
\text { reduzir custos }\end{array}$ & $\begin{array}{l}\text { Baixa diferenciação da oferta (produto e/ou } \\
\text { serviço), vantagem de custo em função da } \\
\text { escala, baixa utilização da capacidade e } \\
\text { demanda de mercado elástica }\end{array}$ \\
\hline \multirow{4}{*}{ : } & Líder de Preços & $\begin{array}{l}\text { Inicia uma mudança } \\
\text { de preços e espera que } \\
\text { os outros o sigam }\end{array}$ & $\begin{array}{l}\text { Alta participação de mercado, facilidade de } \\
\text { detectar mudanças de preços no mercado, } \\
\text { demanda inelástica, alta utilização da } \\
\text { capacidade e vantagens de custo, de escala } \\
\text { e de aprendizado em termos de processos } \\
\text { e sobre o mercado de atuação } \\
\end{array}$ \\
\hline & Paridade de Preços & $\begin{array}{l}\text { Preço fixado pelo mercado } \\
\text { global ou pelo líder } \\
\text { de preços }\end{array}$ & $\begin{array}{l}\text { Desvantagem de custos, baixa participação de } \\
\text { mercado, baixa diferenciação da oferta } \\
\text { (produto e/ou serviço) no mercado, facilidade } \\
\text { de detectar mudaças de preços, demanda de } \\
\text { preços inelástica, demanda de marca elástica } \\
\text { e alta utilização da capacidade }\end{array}$ \\
\hline & Menor Preço & $\begin{array}{l}\text { Possuir sempre que } \\
\text { possível o menor } \\
\text { preço do mercado }\end{array}$ & $\begin{array}{l}\text { Baixa utilização da capacidade produtiva, } \\
\text { baixa participação de mercado, baixa } \\
\text { diferenciação da oferta (produto e/ou serviço), } \\
\text { vantagem de custo, de escala e de } \\
\text { aprendizado, dificuldade de detectar } \\
\text { mudanças de preço e demanda elástica }\end{array}$ \\
\hline & Preço Premium & $\begin{array}{c}\text { Preço mais alto } \\
\text { do mercado, refletido } \\
\text { pela qualidade da oferta }\end{array}$ & $\begin{array}{l}\text { Alta diferenciação da oferta (produto e/ou } \\
\text { serviço), demanda de mercado inelástica, } \\
\text { alta utilização da capacidade e vantagem } \\
\text { de custo em função da escala }\end{array}$ \\
\hline \multirow{2}{*}{ 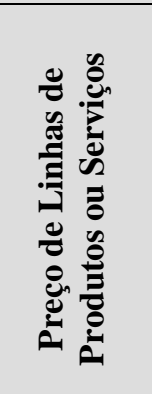 } & $\begin{array}{l}\text { Preço de Produto } \\
\text { ou Serviço } \\
\text { Complementar }\end{array}$ & $\begin{array}{l}\text { Preço baixo para o produto } \\
\text { ou serviço principal } \\
\text { quando serviços } \\
\text { complementares possuem } \\
\text { um preço maior } \\
\end{array}$ & Alto custo de mudança \\
\hline & Preço por Pacote & $\begin{array}{l}\text { Produto é parte de um } \\
\text { pacote de outros produtos } \\
\text { onde o preço proporcione } \\
\text { uma economia aos clientes }\end{array}$ & $\begin{array}{l}\text { Vantagem de custos } \\
\text { Demanda de mercado elástica }\end{array}$ \\
\hline
\end{tabular}




\section{Gabriel Sperandio Milan, Evandro Busata Saciloto, Fabiano Larentis \& Deonir De Toni}

\begin{tabular}{|c|c|c|c|}
\hline & $\begin{array}{c}\text { Valor para } \\
\text { o Cliente }\end{array}$ & $\begin{array}{c}\text { Preço de uma versão dos } \\
\text { produtos a níveis bastante } \\
\text { competitivos com menos } \\
\text { especificações }\end{array}$ & $\begin{array}{c}\text { Dificuldade em detectar mudanças } \\
\text { de preços e demanda do mercado elástica }\end{array}$ \\
\hline
\end{tabular}

Fonte: Adaptada de Noble e Gruca (1999) e Ingenbleek e Van der Lans (2013).

Uma estratégia de preços, portanto, fornece uma definição sistemática dos elementos da estratégia de preços que devem ser gerenciados para obter um melhor desempenho. E estes elementos incluem decisões dos clientes-alvo, identificação das ofertas mais assertivas, ações de comunicação adequadas para convencer tais clientes, critérios par a negociação de vendas e uma metodologia de fixação de preços, o que deve incluir o processo de precificação em si, a estrutura organizacional para realizar os processos de precificação e o desenvolvimento de sistemas de informações gerenciais para fornecer elementos ou evidências para a gestão da implementação da estratégia de preços escolhida (CRESSMAN Jr., 2012).

Nesta direção, Ingenbleek et al. (2003) e Monroe (2003) consideram três práticas em que os gestores utilizam informações para a formação dos preços, ou seja, a percepção de valor para o cliente, os preços praticados pela concorrência e os custos incorridos. Em decorrência disso, as estratégias de preço também podem ser categorizas em três grandes grupos (abordagens): (i) preços baseados em custos; (ii) preços baseados na concorrência; e (iii) preços baseados na percepção de valor para o cliente (NAGLE; HOLDEN, 2003). Estas práticas, algumas vezes, também são chamadas de métodos de fixação de preços (AVLONITIS; INDOUNAS, 2005). Para ampliar tal entendimento, a Figura 3 é elucidativa.

Figura 3 - Abordagens para a fixação do preço

\begin{tabular}{|c|c|c|c|}
\hline Abordagens & $\begin{array}{c}\text { Precificação Baseada } \\
\text { em Custos }\end{array}$ & $\begin{array}{c}\text { Precificação Baseada } \\
\text { na Concorrência }\end{array}$ & $\begin{array}{l}\text { Precificação Baseada } \\
\text { em Valor Percebido }\end{array}$ \\
\hline Definição & $\begin{array}{l}\text { Determinação dos preços } \\
\text { principalmente com dados } \\
\text { da contabilidade de custos }\end{array}$ & $\begin{array}{l}\text { Utiliza como fonte primária } \\
\text { os preços dos concorrentes } \\
\text { como fonte primária } \\
\text { para fixação dos preços }\end{array}$ & $\begin{array}{l}\text { Usa o valor percebido de } \\
\text { uma oferta em um segmento } \\
\text { de clientes pré-definido } \\
\text { como principal fator } \\
\text { para fixação dos preços }\end{array}$ \\
\hline Exemplos & $\begin{array}{l}\text { Custo mais margem, } \\
\text { preços via mark-up e } \\
\text { preço alvo de retorno }\end{array}$ & $\begin{array}{l}\text { Paralelismo de preços, preços } \\
\text { guarda-chuva, preços de } \\
\text { penetração e preços de acordo } \\
\text { com a média de mercado }\end{array}$ & $\begin{array}{l}\text { Precificação de valor } \\
\text { percebido e } \\
\text { desempenho do preço }\end{array}$ \\
\hline $\begin{array}{l}\text { Pontos } \\
\text { Fortes } \\
\end{array}$ & Disponibilidade de dados & Disponibilidade de dados & $\begin{array}{l}\text { Leva em consideração } \\
\text { a perspectiva do cliente }\end{array}$ \\
\hline $\begin{array}{l}\text { Pontos } \\
\text { Fracos }\end{array}$ & $\begin{array}{l}\text { Não leva em conta os } \\
\text { concorrentes, nem a } \\
\text { disponibilidade do } \\
\text { cliente em pagar mais }\end{array}$ & $\begin{array}{l}\text { Não leva a disponibilidade } \\
\text { do cliente em pagar mais }\end{array}$ & $\begin{array}{l}\text { Dados difíceis de se obter } \\
\text { e de se interpretar, podendo } \\
\text { conduzir a preços muito } \\
\text { altos. Necessidade de levar } \\
\text { em conta a rentabilidade } \\
\text { a longo prazo }\end{array}$ \\
\hline
\end{tabular}

REAd | Porto Alegre - Edição 84 - N 2 - Maio / Agosto 2016 - p. 419 - 452 


\begin{tabular}{|c|c|c|c|}
\hline $\begin{array}{c}\text { Avaliação } \\
\text { Geral }\end{array}$ & $\begin{array}{c}\text { Abordagem geralmente } \\
\text { mais frágil }\end{array}$ & $\begin{array}{c}\text { Abordagem subótima para a } \\
\text { definição de preços, mais } \\
\text { apropriada para commodities } \\
\text { e ofertas que não apresentam } \\
\text { elementos de diferenciação }\end{array}$ & $\begin{array}{c}\text { Em geral melhor abordagem, } \\
\text { link direto para a necessidade } \\
\text { dos clientes }\end{array}$ \\
\hline
\end{tabular}

Fonte: Adaptada de Hinterhuber (2008).

\subsection{Relação entre as Estratégias de Preço (ou de Precificação) e o Desempenho do Negócio}

Há poucas investigações sobre as consequências das orientações ou das estratégias de preços sobre o desempenho das empresas (CRESSMAN Jr., 1999; INGENBLEEK, 2007; HINTERHUBER, 2008), e de como as características organizacionais e comportamentais das empresas, principalmente industriais, podem afetar as estratégias de preço (INGENBLEEK, 2007). De acordo com Hinterhuber (2004), o impacto do preço sobre a lucratividade e a rentabilidade é alta, ou seja, o impacto mesmo de pequenos aumentos de preço na lucratividade e rentabilidade empresarial, de longe, excede o impacto de outras alavancagens na gestão de resultados. Em seu estudo, foi detectado que um aumento de $5 \%$ em preços médios de vendas pode aumentar o lucro antes de juros e impostos, o EBIT - Earnings Before Interest and Taxes, em $22 \%$ na média, em comparação ao aumento de $12 \%$ no volume de vendas e $10 \%$ de redução dos custos das mercadorias vendidas, respectivamente.

De todas os elementos disponíveis aos gestores de marketing, o preço é o que possui maior impacto nos resultados (ou desempenho) das empresas. As empresas trabalham no sentido de reduzir e, se possível, eliminar custos, enquanto que o aumento de $1 \%$ nos preços de venda pode trazer resultados expressivos, desde que partindo-se do pressuposto de que este aumento não afetará o volume de vendas, assim como o contrário também é verdadeiro, pois qualquer oscilação nas vendas pode afetar a lucratividade e a rentabilidade das empresas, fazendo dos preços uma decisão crítica (KOHLI; SURIB, 2011; COPPOOLSE, 2013).

De acordo com Dolan e Simon (1998) e Simon, Bilstein e Luby (2008), os gestores deveriam abandonar o raciocínio de uma maior participação de mercado e de um maior volume de negócios em favor de uma visão mais orientada para o lucro e para a rentabilidade. Os resultados indicam que as empresas que praticam um preço superior ao preço de seus concorrentes obtêm uma maior lucratividade e rentabilidade, o que provavelmente tem relação com a entrega de valor superior aos clientes, justificando a cobrança de preços maiores e, consequentemente, melhorando desempenho do negócio. Os gestores são 


\section{Gabriel Sperandio Milan, Evandro Busata Saciloto, Fabiano Larentis \& Deonir De Toni}

instigados realmente a almejarem um preço competitivo, o que pode, às vezes, trazer vantagens frente aos competidores. Porém, o objetivo central da precificação, sob a filosofia do marketing, não é o de as empresas simplesmente praticarem preços inferiores aos adotados pelos concorrentes, e sim maximizar o nível de valor para o cliente e, fundamentalmente, aumentar seu lucro e rentabilidade (LARENTIS et al., 2013; HINTERHUBER; 2008).

\section{MÉTODO DE PESQUISA}

\subsection{Tipo de Pesquisa, População-Alvo e Amostragem}

A proposta de abordagem metodológica à questão central e aos objetivos de pesquisa consistiu na implementação de uma pesquisa quantitativa, de caráter descritivo (MALHOTRA; BIRKS; WILLS, 2012; REMLER; VAN RYZIN, 2012), por meio da realização de uma survey (FOWLER Jr., 2009; FINK, 2013), de corte transversal único (FINK, 2013).

Para a sua implementação, como população-alvo foram consideradas empresas dos ramos metalmecânico, automotivo e eletroeletrônico afiliadas ao SIMECS - Sindicato das Indústrias Metalúrgicas, Mecânicas e de Material Elétrico de Caxias do Sul (RS). A escolha se deu devido à vocação industrial da cidade de Caxias do Sul, que se constitui em um importante polo industrial. A população-alvo, de acordo com dados do SIMECS, compreendeu, inicialmente, 2.600 empresas, que totalizam em torno de 45 mil postos de trabalho.

Para um melhor entendimento sobre a influência das estratégias de precificação sobre o desempenho das empresas, e de posse de uma lista disponibilizada pela entidade (SIMECS), foram excluídas as empresas prestadoras de serviços, como, por exemplo, empresas de tratamento de superfícies metálicas como zincagem e pinturas ou que fabricam produtos que são desenvolvidos por outras empresas, as quais contratam empresas geralmente menores para produzir componentes que posteriormente serão agregados a um produto final de outra empresa. Pode-se citar, como exemplo disso, matrizarias e algumas empresas do ramo de usinagem. Após a definição destes critérios, chegou-se a uma população-alvo de empresas que possuem produtos próprios e que se enquadram nos objetivos desta pesquisa, totalizando, então, 730 empresas, possibilitando uma melhor aderência ao foco do estudo.

Buscou-se estabelecer um critério quanto ao porte das empresas. Para tal, utilizou-se como categorização a receita operacional bruta anual, em convergência aos critérios sugeridos

REAd | Porto Alegre - Edição 84 - N 2 - Maio / Agosto 2016 - p. 419 - 452 
pelo BNDES - Banco Nacional do Desenvolvimento, que considera o porte das empresas como: (i) microempresa: faturamento anual bruto até $\mathrm{R} \$ 2,4$ milhões; (ii) pequena: faturamento anual bruto maior que $\mathrm{R}$ \$ 2,4 milhões e menor de $\mathrm{R}$ \$ 16 milhões; (iii) média empresa: faturamento anual bruto maior que R $\$ 16$ milhões e menor de R \$ 90 milhões; (iv) média-grande: faturamento anual bruto maior que $\mathrm{R} \$ 90$ milhões e menor de R \$300 milhões; e (v) grande: faturamento anual bruto maior que R\$ 300 milhões (BNDES, 2015). Para a realização da pesquisa, utilizou-se uma amostra não probabilística, por conveniência (MALHOTRA; BIRKS; WILLS, 2012).

\subsection{Instrumento de Coleta de Dados}

O instrumento de coleta de dados ou, simplesmente, questionário de pesquisa, assume uma importância fundamental para a busca de evidências empíricas, que servirão como base para que se responda aos objetivos da pesquisa (FOWLER Jr., 2009; MALHOTRA; BIRKS; WILLS, 2012; REMLER; VAN RYZIN, 2012; FINK, 2013).

Cabe ressaltar que o mesmo se configura em uma versão evoluída da versão utilizada nos estudos de Larentis et al. (2013) e Milan et al. (2013), a qual foi construída com base nas escalas propostas por Noble e Gruca (1999), para as estratégias de precificação; de Urdan e Osaku (2005), para os fatores de definição de preços; e de Ingenbleek et al. (2003), para a avaliação da concorrência, do setor de atuação das empresas e do desempenho do negócio, operacionalizadas por meio de escalas do tipo Likert (FOWLER Jr., 2009; BEARDEN; NETEMEYER; HAWS, 2011), de sete pontos, e não de cinco pontos, por haver indícios de melhoria no processo de coleta de dados ou das percepções dos respondentes (WEIJTERS; CABOOTER; SCHILLEWAERT, 2010; LARENTIS; GIACOMELLO, 2012). Os blocos de questões a as escalas utilizadas são apresentados no Apêndice A.

Das 74 variáveis, inicialmente testadas, mediante os resultados estatísticos obtidos nos trabalhos anteriormente realizados (LARENTIS et al., 2013; MILAN et al., 2013), para a presente pesquisa, somente 61 destas variáveis foram consideradas, conferindo uma maior parcimônia no processo de coleta de dados, pois as variáveis eliminadas apresentaram redundância ou falta de poder explicativo. Neste processo, a partir das evidências empíricas, foi utilizado o procedimento de validação de conteúdo, ou validação de face, conforme recomendações encontradas na literatura (MALHOTRA; BIRKS; WILLS, 2012). Para tanto, 


\section{Gabriel Sperandio Milan, Evandro Busata Saciloto, Fabiano Larentis \& Deonir De Toni}

esta nova versão do instrumento de coleta de dados passou pela análise e modificações implementadas por três professores doutores (experts), pesquisadores ligados àárea de marketing.

Como procedimento de validação e finalização do instrumento de coleta de dados, foi aplicado um pré-teste, ou teste piloto, que consiste na aplicação do questionário em uma pequena amostra de respondentes, com características semelhantes às da população-alvo (MALHOTRA; BIRKS; WILLS, 2012). Assim sendo, o pré-teste foi aplicado a um grupo de doze respondentes. O tempo médio para o preenchimento dos doze questionários foi em torno de dez minutos. De forma geral, os respondentes não tiveram dificuldade na compreensão do questionário, uma vez que o mesmo já havia sido, em boa parte, utilizado em estudos anteriores. Não foram necessários ajustes no questionário. Vale ressaltar que os questionários resultantes do pré-teste não foram incorporados à amostra final da pesquisa, sendo, descartados.

\subsection{Processo de Coleta e de Análise dos Dados}

Os questionários foram enviados eletronicamente para as empresas que compreendiam a população-alvo da pesquisa. Para formalizar a solicitação de participação na pesquisa, juntamente com o questionário, foi incluindo um texto explicativo, solicitando que o questionário fosse direcionado ao responsável pela definição de preços da empresa ou que atuasse diretamente no processo de precificação. Com esta abordagem, buscou-se direcionar o instrumento de pesquisa para o responsável na empresa que tivesse maior domínio e relativa experiência no contexto em análise. Dessa maneira, utilizou-se o método de coleta de dados auto administrado, ou seja, de autopreenchimento (FOWLER Jr., 2009; FINK, 2013).

Somado a isso, também era relatado que as respostas seriam analisadas de forma global e não individualmente, informando, de forma objetiva, o intuito apenas acadêmico em relação ao caráter sigiloso quanto à utilização dos dados. A coleta de dados foi realizada entre os meses de junho a agosto de 2014, e o questionário foi enviado para as 730 empresas identificadas (população-alvo), obtendo-se um retorno de 157 questionários (casos válidos), tendo-se, assim, um percentual de $21,5 \%$ de retorno.

O questionário está dividido em blocos de questões (ou variáveis) (vide Apêndice A). Para a análise dos dados, para cada um destes blocos foi utilizada a Análise Fatorial, pelo método dos componentes principais para extração dos fatores, com rotação ortogonal do tipo

REAd | Porto Alegre - Edição 84 - N 2 - Maio / Agosto 2016 - p. 419 - 452 
Varimax (JOHNSON; WICKERN, 2007; MULAIK, 2010; FIELD, 2013). Em complemento, também foi utilizada a Análise de Variância (ANOVA) (HAIR Jr. et al., 2009; FIELD, 2013).

Antes disso, para a definição da amostra final, foram analisados, inicialmente, os missings (não respostas), utilizando-se o método de substituição pela média, conforme recomendações (HAIR Jr. et al., 2009; ENDERS, 2010), e dos outliers (dados atípicos) univariados, pelos $Z$ scores, e multivariados, pela distância de Mahalanobis ( ${ }^{2}$ ) (HAIR Jr. et al., 2009). Sendo assim, dos 157 casos coletados, 4 casos foram eliminados pela incidência de outliers multivariados, resultando em uma amostra final de 153 casos válidos.

\section{APRESENTAÇÃO DOS RESULTADOS}

\subsection{Caracterização da Amostra}

A amostra desta pesquisa pôde ser caracterizada a partir de treze variáveis categóricas: cargo ou função que o respondente desempenha na empresa bem como o tempo de atuação na empresa, ramo principal de atividade exercida pela empresa, tempo de atuação no mercado, número de clientes ativos, número de funcionários, número atual de itens produzidos, faturamento anual bruto, tempo médio dos produtos no mercado, número de lançamentos de novos produtos, margem líquida de lucro, atuação em vendas no mercado externo e se a empresa importa. A seguir são apresentados os principais aspectos do perfil da amostra.

Quanto ao cargo ou função desempenhada nas empresas pesquisadas, 13\% (20) dos respondentes são proprietários das empresas e 12\% (18) dos respondentes possuem o cargo de Diretor nestas empresas. Um número mais expressivo de respondentes se encontra ligado a área comercial das empresas, os quais estão distribuídos nas funções de Diretores, Gerentes e Coordenadores, o que representa 32\% (49) da amostra. Já a área financeira foi representada por $10 \%$ (15) dos respondentes, distribuindo-se entre os cargos de Gerentes e Coordenadores. O restante dos respondentes ficou distribuído em outros cargos ou funções (33\% ou 51).

Sobre o ramo de atividade das empresas, a maior parte delas, 54,9\% (84) pertence ao ramo metalmecânico, 23,5\% (36) ao automotivo e o 21,6\% (33) ao ramo eletroeletrônico. As mesmas apresentam, em média, 21 anos de atuação no mercado, sendo que 38\% (58) delas possuem mais de 20 anos de atuação no mercado e $40 \%$ (61) se encontra na faixa de 10 anos até 20 anos de atuação no mercado. As demais, ou 22\% (34) das empresas, possuem até 10 


\section{Gabriel Sperandio Milan, Evandro Busata Saciloto, Fabiano Larentis \& Deonir De Toni}

anos de atuação no mercado. Além disso, 35,9\% (55) possuem até 100 clientes ativos nos últimos 12 meses e 60,2\% (92) possuem acima de 100 clientes. $O$ restante delas 3,9\% (6) preferiu não responder esta questão ou não souberam informar. No que se refere ao número de funcionários, 35,3\% (54) delas possuem até 19 funcionários, 37,9\% (58) possuem entre 20 e 100 funcionários e as demais $(26,8 \%$ ou 41) possuem mais de 100 funcionários.

Das empresas pesquisadas, 24,2\% (37) possuem um faturamento anual bruto de $\mathrm{R} \$ 2,4$ milhões, as quais são caracterizadas, pelos critérios do BNDES (2015), como microempresas; $34 \%$ (52) possuem faturamento anual de até R 16 milhões e são pequenas empresas; 25,5\% (39) possuem faturamento de até $\mathrm{R} \$ 90$ milhões e são médias empresas; 9,23\% (14) possuem faturamento entre $\mathrm{R} \$ 90$ milhões a $\mathrm{R} \$ 300.000 .000,00$ e são médias-grandes empresas; e 7, $2 \%$ (11) delas possuem faturamento acima de $\mathrm{R} \$ 300.000 .000,00$ e são grandes empresas.

No que diz respeito aos produtos fabricados e comercializados pelas empresas, 64,1\% (98) delas possuem produtos com tempo médio de mercado de até cinco anos e 35,9\% (55) possuem produtos com mais de cinco anos no mercado. Em relação ao lançamento de novos produtos, 34,6\% (53) das empresas declararam ter lançado até três produtos novos nos últimos dois anos, $28,8 \%$ (44) laçaram entre três e dez produtos e 36,6\% (56) declararam ter lançado mais que dez produtos durante este período. Quanto à margem líquida de lucro do último exercício, 2,6\% (4) delas declararam que a margem líquida de lucro resultante foi negativa (prejuízo), enquanto que 54,9\% (84) declaram uma margem líquida de lucro de até 10\%. As demais, 42,5\% (65) das empresas, declararam uma margem líquida de lucro acima de $10 \%$.

Levantou-se, ainda, que 39,9\% (61) das empresas exportam, sendo que estas exportações representam até $10 \%$ do volume de faturamento anual da empresa para 38 empresas dentre as 61 empresas exportadoras e, nas demais (23) empresas, este percentual representa acima de $10 \%$ do volume de faturamento anual. Já 92 empresas $(60,1 \%)$ não efetuam vendas no mercado externo. Em acréscimo, foi questionado em relação à incidência de importações, sendo que 52,3\% (80) das empresas já realizaram importações no mercado externo, enquanto que as demais empresas, $47,7 \%$ (73) delas, não realizaram compras no mercado externo.

REAd | Porto Alegre - Edição 84 - N 2 - Maio / Agosto 2016 - p. 419 - 452 


\subsection{Fatores Relacionados à Formação de Preços nas Empresas}

As variáveis V1 a V15 (vide Apêndice A), que compõem a primeira parte do questionário, estão relacionada aos aspectos considerados, ou não, no processo de definição de preços para os principais produtos das empresas pesquisadas. Nesta parte do questionário, obteve-se três fatores após a eliminação das variáveis V7: “Os sistemas de vendas (comercialização), divulgação e distribuição dos concorrentes" ,V14: "O volume de faturamento (receitas) necessário para que se atinja o ponto de equilíbrio" e V15: "Os investimentos em um novo produto", em função da carga fatorial estar abaixo de 0,5. A variância explicada com estes três fatores foi de 63,75\%, o teste KMO foi de 0,790 e o teste de esfericidade de Bartlett apresentou um qui-quadrado $\left(\chi^{2}\right)$ de 696,517 e significância ( $\mathrm{p}<0,001$ ) apresentando, assim, níveis adequados (JOHNSON; WICKERN, 2007). O Alfa de Cronbach, que em estudos exploratórios, como é o caso desta pesquisa, deve ser de 0,60 ou mais (MALHOTRA; BIRKS; WILLS, 2012). Somente o Fator 3 ficou levemente abaixo desta recomendação, enquanto os outros apresentaram valores satisfatórios (vide Tabela 1).

Tabela 1 - Fatores relacionados à formação de preços nas empresas

\begin{tabular}{|c|c|c|c|c|c|c|}
\hline $\begin{array}{l}\text { Fatores Relacionados } \\
\text { À Formação de Preços }\end{array}$ & Variáveis & $\begin{array}{l}\text { Cargas } \\
\text { Fatoriais }\end{array}$ & $\begin{array}{c}\% \\
\text { Variância } \\
\end{array}$ & $\begin{array}{c}\text { Alfas de } \\
\text { Cronbach } \\
\end{array}$ & Médias & $\begin{array}{l}\text { Desvios } \\
\text { Padrão } \\
\end{array}$ \\
\hline \multirow{5}{*}{$\begin{array}{l}\text { F1: Preço Baseado } \\
\text { na Concorrência }\end{array}$} & V09 & 0,847 & \multirow{5}{*}{33,219} & \multirow{5}{*}{0,826} & \multirow{5}{*}{5,14} & \multirow{5}{*}{1,13} \\
\hline & V05 & 0,798 & & & & \\
\hline & V08 & 0,775 & & & & \\
\hline & V06 & 0,755 & & & & \\
\hline & V10 & 0,619 & & & & \\
\hline \multirow{4}{*}{$\begin{array}{l}\text { F2: Preço Baseado } \\
\text { em Valor Percebido }\end{array}$} & V01 & 0,855 & \multirow{4}{*}{18,630} & \multirow{4}{*}{0,853} & \multirow{4}{*}{5,76} & \multirow{4}{*}{0,962} \\
\hline & V04 & 0,850 & & & & \\
\hline & V02 & 0,809 & & & & \\
\hline & V03 & 0.740 & & & & \\
\hline \multirow{3}{*}{$\begin{array}{l}\text { F3: Preço Baseado } \\
\text { em Custos }\end{array}$} & V11 & 0,766 & \multirow{3}{*}{11,904} & \multirow{3}{*}{0,591} & \multirow{3}{*}{6,24} & \multirow{3}{*}{0,750} \\
\hline & V13 & 0,716 & & & & \\
\hline & V12 & 0,711 & & & & \\
\hline
\end{tabular}

Fonte: Dados da pesquisa

Obs.: Médias calculadas a partir de uma escala de sete pontos.

Dos três fatores, o Fator 1, F1: Preço Baseado na Concorrência, foi formado pelas variáveis V9: “As reações dos concorrentes aos preços da nossa empresa”, V05: “O preço dos produtos dos concorrentes", V08: "A atual estratégia de preços dos concorrentes", V6: "O grau de competição do mercado" e V10: "As vantagens competitivas dos concorrentes no mercado". O Fator 2, F2: Preço Baseado em Valor Percebido, pelas variáveis V01: "As vantagens que o produto oferece ao cliente", V04: "O valor percebido do produto pelos 


\section{Gabriel Sperandio Milan, Evandro Busata Saciloto, Fabiano Larentis \& Deonir De Toni}

clientes (benefícios versus custos)", V02:"O equilíbrio entre as vantagens do produto e o possível preço" e V03: “As vantagens que o produto oferece em comparação aos produtos dos concorrentes". Por último, o Fator 3, F3: Preço Baseado em Custos, pelas variáveis V11: "O custo total do produto", V13: "A margem percentual de lucro definida pela empresa em relação ao preço do produto" e V12: “ Os custos variáveis do produto".

\subsection{Estratégias de Precificação das Empresas}

As variáveis V19 à V30 se referem ao grau de concordância com a estratégia de precificação adotada pela empresa. A partir destas variáveis, procedeu-se a Análise Fatorial, sendo que em função das cargas fatoriais estarem abaixo de 0,5 , as variáveis V20: "Nossos clientes esperam que o preço caia com o tempo", V24: "Oferecemos descontos de forma sistemática e previsível", V27: "Nossos preços estão em nível intermediário no mercado em função da qualidade intermediária de nossos produtos, em relação aos concorrentes" e V28: "Oferecemos produtos a preços competitivos, mas também em uma versão mais simples, com menos características ou opções, se comparadas a outras versões”, foram eliminadas.

Foram identificados, portanto, dois fatores, o Fator 1, F1: Estratégia de Preços Baixos, agrupando as variáveis V21: "Definimos o preço baixo para alavancar o volume de vendas e reduzir custos através da experiência acumulada", V22: "Sempre procuramos ter um preço baixo (menor) no mercado em relação aos concorrentes e V29: "Nossos preços são baixos no mercado em função da qualidade inferior de nossos produtos em relação à concorrência”. E o Fator 2, F2: Estratégias de Preços Altos, pelas variáveis: V23: “Oferecemos produtos a um preço maior nos segmentos de mercados mais importantes e a um preço menor, por meio de descontos, em segmentos menos importantes", V26: "Para produtos que possuem itens complementares ou opcionais (tais como acessórios, partes, peças e serviços), colocamos uma margem de lucro menor no produto básico (central) e margens de lucro maiores nos itens complementares (preço premium)", V30: "Oferecemos pacotes de produtos (um conjunto de vários produtos) em um preço total que permitem aos clientes boas economias se considerassem os produtos comprados individualmente (separadamente)", V19: "Definimos o preço inicialmente alto e então, sistematicamente, o reduzimos o tempo" e V25: "Nossos clientes observam os preços de nossos produtos como indicadores de alta qualidade".

REAd | Porto Alegre - Edição 84 - N 2 - Maio / Agosto 2016 - p. 419 - 452 
Os dois fatores obtiverem um percentual de 59,6\% da variância explicada, muito próximo ao limite recomendado por Hair Jr. et al. (2009), que sugere fatores suficientes para atender um percentual de variância explicada de $60 \%$ ou mais. O teste KMO foi de 0,772 e o de esfericidade de Bartlett resultou e um qui-quadrado $\left(\chi^{2}\right)$ de 369,63 e significância ( $p<0,001)$, sendo que este testes apresentaram níveis adequados, bem como o Alfa de Cronbach para os dois fatores. De posse destes fatores, foram formadas novas variáveis a partir das médias das variáveis que formaram cada fator, deste modo é possível perceber que as empresas pesquisadas tendem a concordar mais (média 4,11) com uma estratégia de preços altos e discordar com uma estratégia de preços baixos (média 2,83). A Tabela 2 traz estes resultados.

Tabela 2 - Estratégia de precificação das empresas

\begin{tabular}{|c|c|c|c|c|c|c|}
\hline Estratégias de Precificação & Variáveis & $\begin{array}{c}\text { Cargas } \\
\text { Fatoriais } \\
\end{array}$ & $\begin{array}{c}\% \\
\text { Variância } \\
\end{array}$ & $\begin{array}{c}\text { Alfas de } \\
\text { Cronbach }\end{array}$ & Médias & $\begin{array}{l}\text { Desvios } \\
\text { Padrão } \\
\end{array}$ \\
\hline \multirow{3}{*}{ F1: Estratégia de Preços Baixos } & V21 & 0,871 & \multirow{3}{*}{40,088} & \multirow{3}{*}{0,824} & \multirow{3}{*}{2,83} & \multirow{3}{*}{1,51} \\
\hline & V22 & 0,870 & & & & \\
\hline & V29 & 0,776 & & & & \\
\hline \multirow{5}{*}{ F2: Estratégias de Preços Altos } & V23 & 0,761 & \multirow{5}{*}{19,494} & \multirow{5}{*}{0,720} & \multirow{5}{*}{4,11} & \multirow{5}{*}{1,23} \\
\hline & V26 & 0,712 & & & & \\
\hline & V30 & 0,644 & & & & \\
\hline & V19 & 0,617 & & & & \\
\hline & $\mathrm{V} 25$ & 0,567 & & & & \\
\hline
\end{tabular}

Obs.: Médias calculadas a partir de uma escala de sete pontos.

O fato de as empresas concordarem mais com uma estratégia de preços altos e menos com a estratégia de preços baixos pode estar ligado às características do mercado em que atuam, uma vez que muitos clientes utilizam os preços como indicador de qualidade, pois produtos com qualidade superior são percebidos como mais caros. Ao analisar a variável V29: "Nossos preços são baixos no mercado em função da qualidade inferior de nossos produtos...", isoladamente, a média desta questão foi de 2,08, sendo que 132 empresas responderam que discordam desta afirmativa. Este número de empresas corresponde a 86,3\% da amostra. Entre elas, 80 discordam totalmente, o que representa 52\% da amostra analisada.

\subsection{Desempenho de Novos Produtos}

As variáveis V16 à V18 tratam do grau de concordância relativo ao desempenho de um novo produto comercializado. As variáveis V16: "O produto ofereceu qualidade superior 


\section{Gabriel Sperandio Milan, Evandro Busata Saciloto, Fabiano Larentis \& Deonir De Toni}

em relação aos concorrentes", V17: "O produto solucionou problemas que os clientes tinham com produtos concorrentes" e V18: "O produto foi bastante inovador e serviu como substituto a outros produtos existentes" compõem esta dimensão de análise. Para estas variáveis, obteve-se um único fator com variância explicada de $72,79 \%$, teste KMO de 0,688 em nível muito próximo ao adequado, e teste de esfericidade de Bartlett com um qui-quadrado $\left(\chi^{2}\right)$ de 159,75 e significância $(\mathrm{p}<0,001)$. Todas as cargas fatoriais estão acima de 0,68 e o Alfa de Cronbach em 0,776 .

O único fator identificado foi denominado F1: Desempenho do Novo Produto. Para tal, a média das variáveis apontou uma média de 5,49, ou seja, as empresas pesquisadas tendem a concordar que o novo produto lançado apresentou um bom desempenho.

Além disso, as variáveis V31: “Objetivo de vendas desde que foi lançado", V32: "Objetivos de participação de mercado desde que foi lançado" e V33: "Margens de lucro esperadas desde o lançamento", relacionadas aos objetivos alcançados com este novo produto, formaram, também, um único fator, denominado F2: Objetivo do Novo Produto, com variância explicada 78,6\%, teste $\mathrm{KMO}$ de 0,698, em níveis muito próximos ao adequado e o de Esfericidade de Bartlett com um qui-quadrado $\left(\chi^{2}\right)$ de 239,032 e significância $(p<0,001)$. Todas as cargas fatoriais resultaram em níveis adequados, ou seja, acima de 0,5. Da mesma forma, a média das variáveis resultou em uma média de 5,41, evidenciando que as empresas pesquisadas atingem seus objetivos esperados com o lançamento de novos produtos.

\subsection{Desempenho em Relação aos Concorrentes}

Esta parte do questionário foi formada por quinze variáveis, procurando-se verificar o desempenho das empresas em relação ao seu concorrente principal. Por meio da Análise Fatorial, e após a eliminação da variável V41: "Preços dos produtos de uma forma geral", com carga fatorial abaixo de 0,5 , obteve-se quatro fatores com variância explicada em níveis adequados de $72,08 \%$, assim como o teste $\operatorname{KMO}(0,851)$ e o teste de esfericidade de Bartlett, com um qui-quadrado $\left(\chi^{2}\right)$ de $1.220,82$ e significância $(p<0,001)$, bem como os Alfas de Cronbach. Tais resultados são apresentados na Tabela 3.

No primeiro fator, F1: Competitividade, foram agrupadas as variáveis V46: "Número de itens de produtos comercializados", V40: "Número de clientes ativo", V36: "Participação de mercado", V48: "Número de lançamentos de novos produtos", V35: "Vantagem de custos

REAd | Porto Alegre - Edição 84 - N 2 - Maio / Agosto 2016 - p. 419 - 452 
devido a economia de escala" e V47: "Número médio de anos no mercado dos principais produtos comercializados. O segundo fator, F2: Mercado, foi formado pelas variáveis V42: "Crescimento médio do volume de vendas", V37: "Diferenciação dos produtos", V43: "Capacidade de detectar mudanças de preços", V34: "Vantagem de custos devido à curva de experiência".

A partir das variáveis que formaram os Fatores 1 e 2, gerou-se uma nova variável para cada fator, calculando-se as médias para estas novas variáveis. Deste modo, foi possível verificar que as empresas pesquisadas entendem que não são altamente competitivas (Fator 1, média de 4,42). No entanto, tendem a declarar que possuem um desempenho um pouco melhor no mercado (Fator 2, média de 5,05) em relação ao seu principal concorrente.

Tabela 3 - Desempenho da empresa em comparação ao principal concorrente

\begin{tabular}{|c|c|c|c|c|c|c|}
\hline $\begin{array}{c}\text { Desempenho da Empresa } \\
\text { em Comparação ao } \\
\text { Principal Concorrente } \\
\end{array}$ & Variáveis & $\begin{array}{l}\text { Cargas } \\
\text { Fatoriais }\end{array}$ & $\begin{array}{c}\% \\
\text { Variância }\end{array}$ & $\begin{array}{l}\text { Alfas de } \\
\text { Cronbach }\end{array}$ & Médias & $\begin{array}{l}\text { Desvios } \\
\text { Padrão }\end{array}$ \\
\hline \multirow{6}{*}{ F1: Competitividade } & V46 & 0,832 & \multirow{6}{*}{42,78} & \multirow{6}{*}{0,873} & \multirow{6}{*}{4,42} & \multirow{6}{*}{1,26} \\
\hline & V40 & 0,826 & & & & \\
\hline & V36 & 0,776 & & & & \\
\hline & V48 & 0,762 & & & & \\
\hline & V35 & 0,627 & & & & \\
\hline & V47 & 0564 & & & & \\
\hline \multirow{4}{*}{ F2: Mercado } & V42 & 0,751 & \multirow{4}{*}{14,55} & \multirow{4}{*}{0,770} & \multirow{4}{*}{5,05} & \multirow{4}{*}{0,97} \\
\hline & V37 & 0,648 & & & & \\
\hline & V43 & 0,573 & & & & \\
\hline & V34 & 0,539 & & & & \\
\hline \multirow{2}{*}{ F3: Custos } & V39 & 0,890 & \multirow{2}{*}{8,70} & \multirow{2}{*}{0,922} & \multirow{2}{*}{4,48} & \multirow{2}{*}{1,29} \\
\hline & V38 & 0,821 & & & & \\
\hline \multirow{2}{*}{$\begin{array}{c}\text { F4: Margem } \\
\text { de Contribuição }\end{array}$} & V45 & 0,893 & \multirow{2}{*}{6,06} & \multirow{2}{*}{0,767} & \multirow{2}{*}{4,74} & \multirow{2}{*}{0,96} \\
\hline & V44 & 0,762 & & & & \\
\hline
\end{tabular}

Obs.: Médias calculadas a partir de uma escala de sete pontos.

O terceiro fator, F3: Custos, formado pelas variáveis V38: “Custos totais” e V39: “Custos fixos", agrupa questões relativas à comparação das empresas quanto ao seu desempenho em termos de custos. As empresas, em geral, percebem que seus custos sejam muito similares aos de seus concorrentes (média de 4,48), o que, de certa forma, acontece com o quarto fator, F4: Margens de Contribuição, que agrupa as questões relacionadas às margens de contribuição, comas variáveis V44: "Margem de contribuição na venda de produtos básicos" e V45: "Margem de contribuição média na venda de produtos complementares" (média de 4,74), demonstrando que suas margens de contribuição estão muito próximas de seus principais concorrentes.

REAd | Porto Alegre - Edição 84 - Nº 2 - Maio / Agosto 2016 - p. 419 - 452 


\section{Gabriel Sperandio Milan, Evandro Busata Saciloto, Fabiano Larentis \& Deonir De Toni}

\subsection{Aspectos Relacionados ao Mercado de Atuação das Empresas}

Esta parte do questionário, foi formada pelas variáveis V49 à V61, as quais estão relacionadas às características intrínsecas ao principal mercado em que as empresas pesquisadas atuam. Nesta etapa da Análise Fatorial, foram obtidos três fatores após a eliminação das variáveis V49: "Crescimento do Mercado como um todo", V58: "Barreiras de entrada no mercado aos novos entrantes" e V61: "Número de itens de produtos comercializados no setor como um todo", em função das cargas fatoriais estarem abaixo de 0,5. Estes três fatores corresponderam a $68,1 \%$ da variância explicada. O teste KMO foi de 0,678 , muito próximo ao níveladequado, o teste de esfericidade de Bartlett apresentou um qui-quadrado $\left(\chi^{2}\right)$ de 629,132 e significância $(\mathrm{p}<0,001)$ e todos os Alfas de Cronbach foram satisfatórios, conforme a Tabela4.

Tabela 4 - Aspectos relacionados ao mercado de atuação das empresas

\begin{tabular}{|c|c|c|c|c|c|c|}
\hline $\begin{array}{c}\text { Aspectos Relacionados ao } \\
\text { Mercado de atuação das Empresas }\end{array}$ & Variáveis & $\begin{array}{l}\text { Cargas } \\
\text { Fatoriais }\end{array}$ & $\begin{array}{c}\% \\
\text { Variância }\end{array}$ & $\begin{array}{l}\text { Alfas de } \\
\text { Cronbach }\end{array}$ & Médias & $\begin{array}{l}\text { Desvios } \\
\text { Padrão }\end{array}$ \\
\hline \multirow{5}{*}{$\begin{array}{l}\text { F1: Competitividade } \\
\text { no Mercado de Atuação }\end{array}$} & V59 & 0,799 & \multirow{5}{*}{35,35} & \multirow{5}{*}{0,803} & \multirow{5}{*}{5,19} & \multirow{5}{*}{0,86} \\
\hline & V51 & 0,723 & & & & \\
\hline & V52 & 0,722 & & & & \\
\hline & V50 & 0,714 & & & & \\
\hline & V60 & 0,695 & & & & \\
\hline \multirow{3}{*}{$\begin{array}{c}\text { F2: Desempenho } \\
\text { do Mercado de Atuação }\end{array}$} & V56 & 0,751 & \multirow{3}{*}{17,92} & \multirow{3}{*}{0,772} & \multirow{3}{*}{4,50} & \multirow{3}{*}{0,96} \\
\hline & V57 & 0,648 & & & & \\
\hline & V53 & 0,573 & & & & \\
\hline \multirow{2}{*}{$\begin{array}{c}\text { F3: Custos } \\
\text { no Mercado de Atuação }\end{array}$} & V54 & 0,890 & \multirow{2}{*}{14,84} & \multirow{2}{*}{0,847} & \multirow{2}{*}{5,32} & \multirow{2}{*}{0,82} \\
\hline & V55 & 0,821 & & & & \\
\hline
\end{tabular}

Fonte: Dados da pesquisa

Obs.: Médias calculadas a partir de uma escala de sete pontos.

O Fator 1, F1: Competitividade no Mercado de Atuação, foi formado pelas variáveis V59: "Poder de barganha dos clientes no setor como um todo", V51: "Sensibilidade dos clientes às diferenças de preços entre as marcas", V52: "Sensibilidade da demanda total às mudanças no preço médio", V50: “Competição de preços" e V60: “Poder de barganha dos fornecedores no setor como um todo". Este fator obteve uma média de 5,19, ou seja, as empresas pesquisadas tendem a declarar que percebem o mercado em que atuam como um mercado competitivo. O Fator 2, F2: Desempenho do Mercado de Atuação, pelas variáveis

REAd | Porto Alegre - Edição 84 - N 2 - Maio / Agosto 2016 - p. 419 - 452 
V56: "Margem de contribuição na venda dos produtos do setor como um todo", V57: "Rentabilidade média do setor como um todo" e V53: "Qualidade dos produtos como um todo", obteve uma média de 4,5, sugerindo que o mercado possui um desempenho intermediário, ou seja, não há um desempenho alto nem baixo, de acordo com a percepção dos respondentes da pesquisa. Por fim, o Fator 3, F3: Custos do Mercado de Atuação, pelas variáveis V54: "Custos totais do setor como um todo" e V55: "Custos fixos do setor como um todo", e obteve uma média de 5,32, indicando que os custos do setor tendem a ser relativamente altos.

\subsection{Práticas de Preço e Desempenho Resultante}

Com o objetivo de identificar possíveis diferenças no desempenho entre as empresas pesquisadas, foi efetuada, também, uma Análise de Variância (ANOVA) entre as variáveis categóricas da pesquisa e as médias das novas variáveis formadas a partir dos fatores identificados. Considerou-se, portanto, como variáveis dependentes as variáveis categóricas V64: "Ramo principal de atividade da empresa", V68: "Número de funcionários", V70: "Faturamento bruto", V71 "Margem líquida", V74 "A empresa exporta?”, V73: "Lançamento de novos produtos", V72: "Tempo médio dos produtos no mercado" e V67: "Número de clientes ativos nos últimos doze meses". E, como variáveis independentes, utilizou-se as variáveis criadas a partir dos fatores gerados durante a etapa da Análise Fatorial.

Segundo Hair Jr. et al. (2009) e Field (2013), a ANOVA só permite que o pesquisador conclua que há diferenças estatísticas em algum ponto entre as médias dos grupos, pois a mesma não identifica onde estão estas diferenças. Deste modo, os autores sugerem que para encontrar estas diferenças, é necessário executar testes de acompanhamento conhecidos como testes post hoc (ou testes de comparações múltiplas).

Como algumas variáveis possuem mais de dois grupos (por exemplo, ramo principal de atividade da empresa, número de funcionários, margem líquida, lançamento de novos produtos e número de clientes ativos), procedeu-se à utilização de um teste de acompanhamento denominado teste post hoc para verificar as diferenças entre as médias. Optou-se, neste caso, pela realização do teste Tukey HSD, o qual, de acordo com Field (2013), é mais preciso, por gerar intervalos de confiança com menor amplitude facilitando, assim, o controle da taxa de erro tipo I. Além disso, o teste de Tukey é mais robusto quando é necessário testar uma grande quantidade de médias. Para os casos em que a homogeneidade

REAd | Porto Alegre - Edição 84 - Nº 2 - Maio / Agosto 2016 - p. 419 - 452 


\section{Gabriel Sperandio Milan, Evandro Busata Saciloto, Fabiano Larentis \& Deonir De Toni}

da variância foi violada, optou-se pelo teste T2 de Tamhane, por ser um teste mais conservador e por ser considerado mais adequado do que o teste de Tukey, quando os tamanhos de subamostras são desiguais (FIELD, 2013).

Primeiramente, verificou-se o desempenho das empresas em relação ao seu ramo de atuação, dentro do polo metalmecânico. A Tabela 5 contém o resultado da ANOVA. Foi destacada como variável dependente o ramo principal de atuação da empresa, divididos, portanto, em metalmecânico (M), automotivo (A) e eletroeletrônico (E) e, como variáveis independentes, as médias das novas variáveis criadas a partir da média dos fatores. Os resultados encontrados com significância ao nível 0,05, estão destacados na Tabela 5 com as letras indicativas (a) ou (a,b) quando há diferença entre uma categoria e as demais.

As empresas do ramo eletroeletrônico tendem a utilizar mais a definição de preços baseado em valor percebido (média de 6,14), do que as empresas do ramo metalmecânico (média de 5,54). Além disso, quando se refere à estratégia de preços (ou de precificação) há uma diferença significativa ao nível de 0,05 entre os três ramos de atividade, uma vez que as empresas do setor metalmecânico tendem a concordar menos com uma estratégia de preços altos (média de 3,78). Por sua vez, as empresas do setor automotivo (média de 4,52) e eletroeletrônico (média de 4,51) indicam utilizar mais este tipo de estratégia.

Tabela 5 - Desempenho das empresa por ramo de atuação

\begin{tabular}{|c|c|c|c|c|c|c|}
\hline Categorias de Análise & Fatores (Variáveis Independentes) & Médias & DP & M & A & $\mathbf{E}$ \\
\hline \multirow{3}{*}{ Definição de Preço } & F1: Preço Baseado na Concorrência & 5,14 & 1,13 & 5,16 & 4,95 & 5,31 \\
\hline & F2: Preço Baseado em Valor Percebido & 5,76 & 0,96 & $5,54 a$ & 5,92 & $6,14 a$ \\
\hline & F3: Preço Baseado em Custos & 6,24 & 0,75 & 6,16 & 6,33 & 6,35 \\
\hline \multirow{2}{*}{ Estratégia de Preço } & F1: Estratégia de Preços Baixos & 2,83 & 1,51 & 3,05 & 2,62 & 2,51 \\
\hline & F2: Estratégias de Preços Altos & 4,11 & 1,23 & $3,78 a, b$ & $4,52 a$ & 4,51b \\
\hline \multirow{4}{*}{$\begin{array}{c}\text { Comparação com } \\
\text { Principal } \\
\text { Concorrente }\end{array}$} & F1: Competitividade & 4,42 & 1,26 & 4,11 & 4,47 & 4,57 \\
\hline & F2: Mercado & 5,05 & 0,97 & 4,79a,b & $5,25 \mathbf{a}$ & $5,48 b$ \\
\hline & F3: Custos & 4,48 & 1,29 & 4,54 & 4,49 & 4,32 \\
\hline & F4: Margens de Contribuição & 4,74 & 0,96 & 4,61 & 4,94 & 4,82 \\
\hline \multirow{3}{*}{ Mercado de Atuação } & F1: Competitividade no Mercado de Atuação & 5,19 & 0,86 & $5,37 \mathbf{a}$ & 5,16 & 4,78a \\
\hline & F2: Desempenho do Mercado de Atuação & 4,51 & 0,96 & 4,61 & 4,50 & 4,24 \\
\hline & F3: Custos no Mercado de Atuação & 5,32 & 0,82 & 5,31 & 5,43 & 5,24 \\
\hline \multirow{2}{*}{ Novos Produtos } & F1: Desempenho do Novo Produto & 5,49 & 1,11 & $5,29 \mathrm{a}$ & 5,59 & $5,90 a$ \\
\hline & F2: Objetivo do Novo Produto & 5,10 & 1,16 & $4,81 a, b$ & $5,46 \mathbf{a}$ & $5,46 b$ \\
\hline & Número de Casos Analisados (Empresas) & 153 & - & 84 & 36 & 33 \\
\hline
\end{tabular}

Obs.: Ramos de atuação: M: metalmecânico, A: automotivo e E: eletroeletrônico; DP: Desvio Padrão.

REAd | Porto Alegre - Edição 84 - N 2 - Maio / Agosto 2016 - p. 419 - 452 
Diante da comparação com seus concorrentes, é possível observar que as empresas dos ramos eletroeletrônico (E) e automotivo (A) apontam para um melhor desempenho em relação a seu principal concorrente no mercado. Por outro lado, as empresas ligadas ao ramo metalmecânico (M) indicam ter um desempenho menor perante estes dois setores, o que pode ser um indício da maior competitividade do mercado, especificamente enfrentado pelas empresas do ramo metalmecânico. Tal constatação, de que a competitividade do mercado demonstra-se em níveis mais altos pode ser observada ao compararmos a atuação de mercado em que a competitividade percebida pelas empresas do ramo metalmecânico é maior (média 5,37 ) do que para as empresas do setor eletroeletrônico (média de 4,78), por exemplo.

Quanto ao lançamento de novos produtos, as empresas do ramo eletroeletrônico tendem a declarar que obtiveram melhor desempenho quanto ao lançamento de um novo produto (média de 5,90) dos demais ramos de atividade, principalmente em relação ao ramo metalmecânico, sendo que a diferença foi estatisticamente significante (média de 5,29). Além disso, as empresas dos ramos eletroeletrônico (média de 5,46) e automotivo (média de 5,46) indicam que os objetivos traçados para os novos produtos tendem a ser melhor atingidos do que as empresas do ramo metalmecânico (média de 4,81).

A variável categórica V70: "Faturamento anual bruto", foi reagrupada em uma nova variável com duas categorias, a qual agrupou as micros e pequenas empresas, com faturamento anual bruto até $\mathrm{R} \$ 16$ milhões ( $<=16 \mathrm{M})$ e médias e grandes empresas com faturamento anual bruto acima de $\mathrm{R} \$ 16$ milhões (>16M). A partir destas novas variáveis, por meio da ANOVA, buscouse identificar as diferenças em relação aos fatores identificados na Análise Fatorial. A Tabela 6 contém as diferenças das médias em níveis de significância de 0,05 indicadas com a letra (a).

Tabela 6 - Faturamento das empresas

\begin{tabular}{c|lcccc}
\hline Categorias de Análise & \multicolumn{1}{|c}{ Fatores (Variáveis Independentes) } & Médias & DP & $\begin{array}{c}<=\mathbf{R} \$ \\
\mathbf{1 6 M}\end{array}$ & $\begin{array}{c}>\mathbf{R} \$ \\
\mathbf{1 6 M}\end{array}$ \\
\cline { 2 - 6 } Definição de Preço & F1: Preço Baseado na Concorrência & 5,14 & 1,13 & 5,06 & 5,26 \\
& F2: Preço Baseado em Valor Percebido & 5,76 & 0,96 & $\mathbf{5 , 6 1 a}$ & $\mathbf{5 , 9 6 a}$ \\
& F3: Preço Baseado em Custos & 6,24 & 0,75 & 6,30 & 6,17 \\
\hline \multirow{2}{*}{ Estratégia de Preço } & F1: Estratégia de Preços Baixos & 2,83 & 1,51 & $\mathbf{3 , 0 6 a}$ & $\mathbf{2 , 5 2 a}$ \\
& F2: Estratégias de Preços Altos & 4,11 & 1,23 & $\mathbf{3 , 8 0 a}$ & $\mathbf{4 , 5 4 a}$ \\
\hline \multirow{2}{*}{$\begin{array}{c}\text { Comparação com } \\
\text { Principal Concorrente }\end{array}$} & F1: Competitividade & 4,42 & 1,26 & $\mathbf{4 , 0 6 a}$ & $\mathbf{4 , 9 2 a}$ \\
& F2: Mercado & 5,05 & 0,97 & $\mathbf{4 , 8 3 a}$ & $\mathbf{5 , 3 5 a}$ \\
\cline { 2 - 6 } & & & &
\end{tabular}

REAd | Porto Alegre - Edição 84 - № 2 - Maio / Agosto 2016 - p. 419 - 452 
Gabriel Sperandio Milan, Evandro Busata Saciloto, Fabiano Larentis \& Deonir De Toni

\begin{tabular}{c|lcccc}
\hline & F3: Custos & 4,48 & 1,29 & 4,41 & 4,58 \\
& F4: Margens de Contribuição & 4,74 & 0,96 & 4,64 & 4,87 \\
\hline \multirow{3}{*}{ Mercado de Atuação } & F1: Competitividade no mercado de atuação & 5,19 & 0,86 & $\mathbf{5 , 3 6 a}$ & $\mathbf{4 , 9 6 a}$ \\
& F2: Desempenho do Mercado de Atuação & 4,51 & 0,96 & 4,45 & 4,56 \\
& F3: Custos do Mercado de Atuação & 5,32 & 0,82 & 5,27 & 5,39 \\
\hline \multirow{2}{*}{ Novos Produtos } & F1: Desempenho do Novo Produto & 5,49 & 1,11 & $\mathbf{5 , 2 2 a}$ & $\mathbf{5 , 8 7 a}$ \\
& F2: Objetivo do Novo Produto & 5,10 & 1,16 & $\mathbf{4 , 9 0 a}$ & $\mathbf{5 , 3 8 a}$ \\
\hline & Número de Casos Analisados (Empresas) & $\mathbf{1 5 3}$ & - & $\mathbf{8 9}$ & $\mathbf{6 4}$ \\
\hline
\end{tabular}

Fonte: Dados da pesquisa

Obs.: M: faturamento anual em milhões de Reais (R\$); DP: Desvio Padrão.

Em relação à definição de preços, as empresas que possuem um faturamento anual acima de $\mathrm{R}$ \$ 16 milhões (empresas médias e grandes) tendem a concordar mais com uma definição de preços baseado em valor percebido (média de 5,96). Já as empresas que possuem faturamento anual abaixo de $\mathrm{R} \$ 16$ milhões (micro e pequenas empresas) tendem a discordar menos (média de 3,06) com uma estratégia de preços baixos, em relação às empresas com maior faturamento (média de 2,52). Quando estas empresas se comparam com o principal concorrente, as empresas que apresentam um faturamento anual abaixo de $\mathrm{R} \$ 16$ milhões (micro e pequenas empresas tendem a ter um desempenho mais baixo em relação à competitividade de mercado (média de 4,06) e em relação ao desempenho diante de seu principal concorrente (média de 4,83). Por sua vez, empresas com maior faturamento tendem a ter um melhor desempenho em relação à competitividade (média de 4,92) e em relação ao mercado (média de 5,35), podendo haver ligação com aspectos relacionados ao mercado de atuação, ou seja, um mercado mais competitivo percebido pelas empresas com menor faturamento (média de 5,36), no qual estão inseridas.

No que tange à variável categórica V71: "Margem líquida de lucro (após impostos e contribuição social)", esta foi reagrupada em uma nova variável com três categorias, empresas com: (i) margem líquida de lucro menor que 5\% (<=5\%); (ii) margem líquida de lucro maior que $5 \%$ até $10 \%$ (>5\% a 10\%); e (iii) margem líquida de lucro superior a $10 \%$ (>10\%). Dessa forma, foi possível obter uma melhor compreensão sobre esta variável, aliás, como mostra a Tabela 7, na qual constam os dados comparativos entre as médias significantes ao nível de 0,05, indicados com as letras (a) ou (a,b), nos casos onde há diferenças em mais de uma categoria entre as médias desta variável categórica em relação aos fatores analisados.

Tabela 7 - Margem líquida de lucro das empresas

Categorias de Análise $\quad$ Fatores (Variáveis Independentes) $\quad$ Médias DP $\quad<=5 \% \quad>5 \%$ a $10 \% \quad>10 \%$

REAd | Porto Alegre - Edição 84 - N 2 - Maio / Agosto 2016 - p. 419 - 452 
AS ESTRATÉGIAS DE PRECIFICAÇÃO E O DESEMPENHO DAS EMPRESAS

\begin{tabular}{|c|c|c|c|c|c|c|}
\hline \multirow{3}{*}{ Definição de Preço } & F1: Preço Baseado na Concorrência & 5,14 & 1,13 & 4,94 & 5,21 & 5,19 \\
\hline & F2: Preço Baseado em Valor Percebido & 5,76 & 0,96 & $5,00 a, b$ & $5,81 \mathrm{a}$ & $6,12 b$ \\
\hline & F3: Preço Baseado em Custos & 6,24 & 0,75 & 6,09 & 6,30 & 6,27 \\
\hline \multirow{2}{*}{ Estratégia de Preço } & F1: Estratégia de Preços Baixos & 2,83 & 1,51 & 4,05 & 2,70 & 2,30 \\
\hline & F2: Estratégias de Preços Altos & 4,11 & 1,23 & 3,32a & 3,84a,b & $4,75 b$ \\
\hline \multirow{4}{*}{$\begin{array}{c}\text { Comparação } \\
\text { com Principal } \\
\text { Concorrente }\end{array}$} & F1: Competitividade & 4,42 & 1,26 & 3,81a,b & $4,66 a$ & $\mathbf{4 , 5 3 b}$ \\
\hline & F2: Mercado & 5,05 & 0,97 & $4,20 \mathrm{a}, \mathrm{b}$ & 4,98a & $5,55 \mathrm{~b}$ \\
\hline & F3: Custos & 4,48 & 1,29 & 3,84a,b & $4,66 a$ & $4,67 b$ \\
\hline & F4: Margens de Contribuição & 4,74 & 0,96 & 4,16a,b & $4,69 a$ & $5,08 b$ \\
\hline \multirow{3}{*}{ Mercado de Atuação } & $\begin{array}{l}\text { F1: Competitividade no Mercado de } \\
\text { Atuação }\end{array}$ & 5,19 & 0,86 & 5,72a,b & $5,23 a$ & $4,88 b$ \\
\hline & $\begin{array}{l}\text { F2: Desempenho do Mercado de } \\
\text { Atuação }\end{array}$ & 4,51 & 0,96 & $4,17 a$ & 4,57 & $4,63 b$ \\
\hline & F3: Custos no Mercado de Atuação & 5,32 & 0,82 & 5,13 & 5,42 & 5,35 \\
\hline \multirow{2}{*}{ Novos Produtos } & F1: Desempenho do Novo Produto & 5,49 & 1,11 & 4,46a,b & $\mathbf{5 , 5 a}$ & 6,02b \\
\hline & F2: Objetivo do Novo Produto & 5,10 & 1,16 & $4,09 a, b$ & $5,07 \mathbf{a}$ & $5,67 b$ \\
\hline & Casos Analisados (Empresas) & 153 & - & 34 & 54 & 65 \\
\hline
\end{tabular}

Obs.: DP: Desvio Padrão.

Fonte: Dados da pesquisa

De acordo com os dados, as empresas que indicam ter uma margem líquida de lucro acima de $10 \%$ tendem a concordar mais com a utilização do método de definição de preços baseado no valor percebido (média de 6,12), havendo uma diferença estatisticamente significante em relação às empresas com margem líquida de lucro menor que 5\% (média de 5,00). Quanto à utilização das estratégias de precificação, a adoção de uma estratégia de preços altos é mais associada a empresas com margem líquida de lucro acima de 10\%, o que sugere que a formação de preços baseada em valor percebido e uma estratégia de preços altos tendem a ser mais lucrativas, portanto, gerando um desempenho superior em relação a outras estratégias. Por outro lado, as empresas que declaram ter menores resultados, ou seja, margem líquida de lucro inferior a 5\% tendem a concordar menos com uma estratégia de preços altos.

Entre as empresas que fizeram parte da pesquisa, chama atenção o fato de as empresas com menores margens líquidas de lucro apontarem que sua competitividade, desempenho no mercado, desempenho em termos de seus custos e suas margens líquidas de lucro serem considerados abaixo do desempenho do seu principal concorrente. De modo geral, empresas com menor lucro aparentam ser mais influenciadas pelos aspectos externos (relacionados ao mercado de atuação), por perceberem um mercado mais competitivo para a empresa, ou seja, as empresas com margem líquida de lucro menor que 5\% indicam que a competitividade do 


\section{Gabriel Sperandio Milan, Evandro Busata Saciloto, Fabiano Larentis \& Deonir De Toni}

mercado em que atuam é percebida com mais alta (média de 5,72) do que para empresas com margem líquida de lucro entre 5\% a 10\% (média de 5,23) e empresas com margem líquida de lucro acima de 10\% (média de 4,88). As empresas com margem líquida de lucro menor que $5 \%$ tendem a perceber que o seu desempenho no mercado de atuação é mais baixo (média de 4,17) do que para empresas com margens líquidas de lucro acima de 10\% (média de 4,63).

Conforme dito anteriormente, as empresas que definem preços mais altos que seus competidores apresentam um lucro superior, fato este também apontado quando estas empresas se comparam com o seu principal concorrente, ou seja, as empresas tendem a apontar um desempenho superior em relação ao seu principal concorrente.

Em relação a novos produtos, as empresas com maior margem líquida de lucro, acima de $10 \%$, tendem a verificar que seus produtos apresentam um desempenho superior em relação aos de seus concorrentes (média de 6,02), assim como o alcance dos objetivos propostos para estes novos produtos (média de 5,57), o que não é percebido, na mesma intensidade, em empresas com margens líquidas de lucro menores, nas quais o desempenho do produto é menor (média de 4,46), bem como o alcance dos objetivos para estes novos produtos (média de 4,09). Desta maneira, o lançamento de um produto, com qualidade superior, pode estar associado a uma estratégia de preços baseado em valor percebido, trazendo uma maior margem líquida de lucro e um desempenho superior em relação aos concorrentes.

\section{CONSIDERAÇÕES FINAIS}

Melhorar a lucratividade e a rentabilidade das empresas é objetivo de todo o gestor. Para isso, a decisão de preços é uma das mais importantes decisões atinentes à gestão, sendo esta complexa e desafiadora (MONROE, 2003). Deste modo, empresas que não gerenciam seus preços perdem o controle sobre os mesmos, corroendo a sua lucratividade e a sua rentabilidade (SOON, 2011; HITERHUBER, 2004). Neste horizonte, esta pesquisa buscou compreender os aspectos relacionados à definição das estratégias de preços (precificação) e os fatores utilizados na tomada de decisão, bem como a escolha das estratégias e sua relação com o desempenho das empresas do setor industrial, mais especificamente de 153 empresas ligadas aos ramos metalmecânico, automotivo e eletroeletrônico localizadas na Serra Gaúcha.

Dentre as três abordagens apresentadas, o preço baseado em valor percebido é cada vez mais reconhecido como superior às outras abordagens (preço baseado em custos e nos

REAd | Porto Alegre - Edição 84 - N 2 - Maio / Agosto 2016 - p. 419 - 452 
concorrentes) (INGENBLEEK, 2007; HINTERHUBER; LIOZU, 2012; 2014). A definição de preços baseados em valor percebido é a prática de preços que procura capturar uma parte do impacto econômico de uma parte vendedora sobre a satisfação de uma parte compradora, concentrando os esforços na satisfação do cliente (CRESSMAN Jr., 2012) e, consequentemente, potencializando o aumento do lucro e da rentabilidade (HINTERHUBER, 2008). Diante disso, verificou-se que as empresas pesquisadas possuem diferenças quanto à utilização das abordagens para a definição de seus preços. Por exemplo, empresas ligadas ao ramo eletroeletrônico utilizam mais o preço baseado em valor percebido do que empresas do ramo metalmecânico.

Empresas que adotam esta abordagem apresentam maior nível de faturamento anual e uma maior margem líquida de lucro (acima de 10\%). É possível inferir que as empresa que utilizam a definição de preços baseada em valor percebido, a qual é considerada superior em relação aos resultados obtidos pelas outras empresas, contribui para um melhor desempenho do negócio (HINTERHUBER, 2008; LARENTIS et. al, 2013; MILAN et al., 2013). Além de uma margem líquida de lucro maior, foi possível identificar que estas empresas apresentaram volumes de faturamento anual superiores e um maior número de lançamentos de novos produtos, o que pode estar relacionado a uma entrega de valor superior ao cliente, demandada por estes lançamentos mais frequentes atendendo, assim, as necessidades do mercado.

Cabe refletir que empresas de menor porte tendem a operar com margens líquidas de lucro e de rentabilidade reduzidas e com baixo grau de diferenciação dos seus produtos, reduzindo, consequentemente, a lucratividade e a rentabilidade do negócio, ameaçando, inclusive, a sua sobrevivência. Aliás, empresas de maior porte podem exercer influências sobre a precificação dos produtos no mercado por deterem um alto poder de barganha perante os seus fornecedores. Deste modo, os gestores necessitam buscar alternativas para que não fiquem limitados a poucos clientes, ou seja, investir em novos produtos que possam atingir um número maior de clientes potenciais, evitando ou minimizando a pressão exercida pelos competidores, ainda mais quando houver uma carteira de clientes reduzida, com altos níveis de concentração no faturamento da empresa.

Por conseguinte, capturar o valor percebido pelos clientes (atuais e novos) em relação aos produtos comercializados pode ser uma alternativa focada em melhores resultados. Mas, para tal, é necessário que este valor seja, posteriormente, comunicado e efetivamente entregue aos clientes. Sendo assim, capacitar a equipe de vendas de acordo com as estratégias estabelecidas pode auxiliar neste processo, que somado a incentivos aos profissionais de 


\section{Gabriel Sperandio Milan, Evandro Busata Saciloto, Fabiano Larentis \& Deonir De Toni}

vendas que priorizem melhores margens de lucro líquido e de rentabilidade, não apenas maiores volumes de negócios (ou vendas), possam direcionar a empresa para uma política de preços mais orientada a melhores resultados em uma perspectiva de longo prazo.

Ao analisar as estratégias de preços, também se verificou que existe uma diferença significativa entre os ramos de atuação das empresas pesquisadas. As empresas pertencentes ao ramo metalmecânico, de modo geral, não utilizam de forma predominante a estratégia de preços baixos, porém, há uma diferença quanto ao seu porte, no que diz respeito ao número de funcionários destas empresas. Estas diferenças se encontram entre as empresas com até 19 funcionários (média de 3,38) e empresas entre 20 e 100 funcionários (média de 2,39), ou seja, as empresas entre 20 e 100 funcionários utilizam menos a estratégia de preços baixos do que as demais empresas. Quanto à adoção de estratégias de preços altos, as quais apresentaram diferenças significativas entre os diferentes ramos de atividades, número de funcionários, faturamento das empresas e margem líquida de lucro, pôde-se notar que empresas que praticam a estratégia de preços altos possuem melhores margens líquidas de lucro.

Os gestores, portanto, precisam compreender o contexto mercadológico no qual suas empresas estão inseridas, considerando os aspectos externos e internos para a escolha da melhor abordagem para a formação de preços e para a sua estratégia de precificação (INGENBLEEK;VANDER LANS; 2013; MILAN et al., 2013). Além disso, devem compreender a relação do valor percebido pelos clientes e o grau de satisfação com os produtos (benefícios esperados versus sacrifícios incorridos), e transformá-los em informações que auxiliem a tomada de decisão acerca dos preços. Para isso, a utilização de um sistema de informação estruturado pode contribuir para auxiliar nas decisões de preços. As decisões de preços, por conseguinte, devem ser constantemente revisadas e ajustadas, dadas as incertezas apresentadas no mercado.

Para isso, sugere-se aos gestores desenvolverem ou implementarem instrumentos de controle (relatórios) efetivos no que diz respeito ao acompanhamento dos preços, tanto da empresa quanto dos concorrentes, definindo indicadores de desempenho, associados a metas, que possam auxiliar na consolidação de estratégias e políticas de precificação adequadas, ou que sirvam para indicar a alteração ou para minimizar o efeito da adoção de estratégias e políticas de precificação equivocadas.

Como algumas áreas (departamentos ou setores) da empresa, como, por exemplo, Marketing, Vendas (ou Comercial) e Administrativo-Financeira podem possuir objetivos distintos, a implementação estratégica de preços envolve encontrar um equilíbrio entre estas

REAd | Porto Alegre - Edição 84 - N 2 - Maio / Agosto 2016 - p. 419 - 452 
áreas (LANCIONI; SHAU; SMITH, 2005). Com base nisso, as empresas deveriam estabelecer um Comitê de Preços (ou de Precificação), com representantes destas áreas, cada qual com sua perspectiva e entendimento sobre o negócio, o mercado e os clientes, sendo responsável, dentre outras coisas, pela decisão e gestão da estratégia e da política de preços da empresa, pelo acompanhamento dos resultados e pelas possíveis correções de rumo, quando necessárias, o que exigirá a cooperação entre as áreas em prol da geração de um melhor desempenho do negócio como um todo, não apenas da Área de Vendas (ou Comercial.

\section{REFERÊNCIAS}

AVLONITIS, G.; INDOUNAS, A. Pricing objectives and pricing methods in the service sector. Journal of Services Marketing, v. 19, n. 1, p. 47-57, 2005.

BAKER, W. L.; MARN, M. V., ZAWADA, C. The price advantage. $2^{\text {nd }}$ edition. New York: Wiley Finance, 2010.

BEARDEN, W. O.; NETEMEYER, R. G.; HAWS, K. L. Handbook of marketing scales: multi-item measures for marketing and consumer behavior research. $3^{\text {rd }}$ edition. Thousand Oaks: Sage Publications, 2011.

BNDES-Banco Nacionaldo Desenvolvimento. Site institucional.Disponívelem: www.bndes. gov.br/SiteBNDES/bndes/bndes_pt/Institucional/apoio_financeiro/porte. Acesso:15 mai.2015. CHURCHILL Jr., G. A.; PETER, J. P. Marketing: criando valor para o cliente. 3. ed. São Paulo: Saraiva, 2013.

COPPOOLSE, R. Implementing effective pricing strategies: tool for tracking prices. In: HINTERHUBER, A.; LIOZU, S. (eds.). Innovation in pricing: contemporary theories and best practices. New York: Routledge, 2013. chapter, 21, p. 310-322.

CRESSMAN Jr., G. E. Commentary on industrial pricing: theory and managerial practice. Marketing Science, v. 18, n. 3, p. 455-457, 1999.

CRESSMAN Jr., G. E. Value-based pricing: a state-of-the-art review. In: LILIEN, G.; GREWAL, R. (eds.). Handbook on business to business marketing. Massachusetts: Edward Elgar Publishing, 2012. chapter 14, p. 246-269.

DIAMANTOPOULOS, D. Pricing: theory and evidence-a literature review. In: BAKER, J. M. (ed.). Perspectives on marketing management. Chichester: Wiley \& Sons, 1991. p. 61-193. DOLAN, R. J.; SIMON, H. O poder dos preços: as melhores estratégias para ter lucro. São Paulo: Futura, 1998.

DUTTA, S.; ZBARACKI, M. J.; BERGEN, M. Pricing process as a capability: a resourcebased perspective. Strategic Management Journal, v. 24, n. 7, p. 615-630, 2003. 


\section{Gabriel Sperandio Milan, Evandro Busata Saciloto, Fabiano Larentis \& Deonir De Toni}

ENDERS, C. K. Applied missing data analysis. New York: The Gilford Press, 2010.

FIELD, A. Discovering statistics using IBM SPSS statistics. $4^{\text {th }}$ edition. Thousand Oaks: Sage Publications, 2013.

FINK, A. How to conduct surveys: a step-by-step guide. $5^{\text {th }}$ edition. Thousand Oaks: Sage Publications, 2013.

FOWLERJr.,F.J.Survey researchmethods. $4^{\text {th }}$ edition. Thousand Oaks: SagePublications, 2009.

HAIR Jr., J. F.; BLACK, W. C.; BABIN, B. J.; ANDERSON, R. E.; TATHAM, R. L.

Análise multivariada de dados. 6. ed. Porto Alegre: Bookman, 2009.

HINTERHUBER, A. Towards value-based pricing - an integrative framework for decision making. Industrial Marketing Management, v. 33, n. 8, p. 765-778, 2004.

HINTERHUBER, A. Customer value-based pricing strategies: why companies resist. Journal of Business Strategy, v. 29, n. 4, p. 41-50, 2008.

HINTERHUBER, A.; LIOZU, S. Is it time to rethink your pricing strategy? Sloan Management Review, v. 53, n. 4, p. 69-77, 2012.

HINTERHUBER, A.; LIOZU, S. Is innovation in pricing your next source of competitive advantage ? Business Horizons, v. 57, n. 3, p. 413- 423, 2014.

HOLLENSEN, S. Marketing management: a relationship approach. London: McGraw-Hill, 2006.

INGENBLEEK, P. Value-informed pricing in its organizational context: literature review, conceptual framework, and directions for future research. Journal of Product \& Brand Management, v. 16, n. 7, p. 441-458, 2007.

INGENBLEEK, P.;DEBRUYNE, M.;FRAMBACK, R.; VERHALLEN, T. M. Successful new product pricing practices:acontingency approach. MarketingLetters, v. 14,n.4,p. 289-305, 2003.

INGENBLEEK, P.; FRAMBACH, R. T.; VERHALLEN, T. Best practices for new product pricing: impact on market performance and price level under different conditions. Journal of Product Innovation Management, v. 30, n. 3, p. 560-573, 2013.

INGENBLEEK, P.; VAN DER LANS, I. A. Relating price strategies and price-setting practices. European Journal of Marketing, v. 47, n. 1/2, p. 27-48, 2013.

JOHNSON, R. A.; WICKERN, D. W. Applied multivariate statistical analysis. $6^{\text {th }}$ edition. Upper Saddle River: Pearson / Prentice Hall, 2007.

REAd | Porto Alegre - Edição 84 - № 2 - Maio / Agosto 2016 - p. 419 - 452 
KOHLI, C.; SURIB, R. The price is right? Guidelines for pricing to enhance profitability. Business Horizons, v. 54, n. 6, p. 563-573, 2011.

KOTLER, P. Administração de marketing. 10. ed. São Paulo: Prentice Hall, 2000.

LANCIONI, R. A strategic approach to industrial product pricing: the pricing plan.

Industrial Marketing Management, v. 34, n. 2, p. 177-183, 2005.

LANCIONI, R.; SCHAU, H. J.; SMITH, M. F. Intraorganizational influences on business-tobusiness pricing strategies: a political economy perspective. Industrial Marketing Management, v. 34, n. 2, p. 123-131, 2005.

LARENTIS, F.; GIACOMELLO, C. P. Análise da importância em pesquisas de satisfação através da regressão múltipla: estudo do efeito de diferentes pontos de escala. In: V EMA Encontro de Marketing. Anais... Curitiba: ANPAD, 2012.

LARENTIS, F.; MILAN, G. S.; DE TONI, D.; GAVA, A. M. Formação e estratégias de preços: um estudo quantitativo-descritivo sobre as práticas de empresas da Serra Gaúcha. Revista Análise, v. 24, n. 1, p. 28-41, 2013.

LIOZU, S. M.; HINTERHUBER, A. Industrial product pricing: a value-based approach. Journal of Business Strategy, v. 33, n. 4, p. 28-39, 2012.

LIOZU, S. M.; HINTERHUBER, A. The confidence factor in pricing: driving firm performance. Journal of Business Strategy, v. 34, n. 4, p. 11-21 2013.

LIOZU, S. M., HINTERHUBER, A.; BOLAND R.; PERELLI, S. Mindful pricing: transforming organizations through value-based pricing. Journal of Strategic Marketing, v. 20, n. 3, p. 197-209, 2012.

MALHOTRA, N. K.; BIRKS, D.; WILLS, P. Marketing research: applied approach. $4^{\text {th }}$ edition. New York: Pearson, 2012.

MILAN, G. S.; DE TONI, D.; LARENTIS, F.; GAVA, A. M. Relação entre estratégias de preços e custeio. RCA - Revista de Ciências da Administração, v. 1, n. 1, p. 229-244, 2013.

MONROE, K. B. Pricing making profitable decisions. $3^{\text {rd }}$ edition. New York: McGrawHill/Irwin, 2003.

MSI - Marketing Science Institute. Institutional site. Disponível em: www.msi.org/ research/2014-2016-research-priorities. Acesso: 02 mar. 2015.

MULAIK, S. A. Foundations of factor analysis. $2^{\text {nd }}$ edition. Boca Raton: Taylor \& Francis Group, 2010.

NAGLE,T.T.;HOLDEN,R.K.Estratégiasetáticasdepreços.3.ed.SãoPaulo:PrenticeHall,2003.

NICHELE, M.; MILAN, G. S. Fundamentos estratégicos e decisões de preço. In: MILAN, G. S.; BRANCHI, N. V. L. (org.). Administração mercadológica: teoria e pesquisas. Volume 


\section{Gabriel Sperandio Milan, Evandro Busata Saciloto, Fabiano Larentis \& Deonir De Toni}

2. Caxias do Sul: EDUCS, 2006. cap. 7, p. 151-180.

NOBLE, P. M.; GRUCA, T. S. Industrial pricing: theory and managerial practice. Marketing Science, v. 18, n. 3, p. 435-454, 1999.

OXENFELDT, A. R. A decision-making structure for price decisions. Journal of Marketing, v. 37, p. 48-53, 1973.

RAMOS, P. M.; MAYA, P. C. C.; BORNIA, A. C. Um estudo científico do componente preço e sua relação com o marketing mix de produto brasileiro de exportação: uma pesquisa multicasos nas empresas do consórcio de exportação de calçados de São João Batista/Santa Catarina. In: XXIX ENANPAD - Encontro da Associação Nacional de Pós-Graduação e Pesquisa em Administração. Anais... Brasília: ANPAD, 2005.

SAXENA, R. Marketing management. $4^{\text {th }}$ edition. New Delhi: Tata McGraw-Hill, 2009. SHIPLEY, D.; JOBBER, D. Integrative pricing via the pricing wheel. Industrial Marketing Management, v. 30, n. 3, p. 301-314, 2001.

SIMON, H.; BILSTEIN, F. F.; LUBY, F. Gerenciar para o lucro, não para a participação de mercado. Porto Alegre: Bookman, 2008.

SOON, W. A review of multi-product pricing models. Applied Mathematics and Computation, v. 217, n. 21, p. 8.149-8.165, 2011.

TELLIS, G. J. Beyond the many faces of price: an integration of pricing strategies. Journal of Marketing, v. 50, n. 4, p. 146-60, 1986.

TORRES, U. P. P.; MARTINS, H. C. Análise estratégica das áreas de marketing e finanças no processo de formação e manutenção dos preços: o caso da montadora Fiat Automóveis S/A. In: II EMA - Encontro de Marketing. Anais... Rio de Janeiro: ANPAD, 2006.

REMLER, D. K.; VAN RYZIN, G. G. Research methods in practice: strategies for description and causation. Thousand Oaks: Sage Publications, 2011.

STIVING, M. B2B pricing systems: proving ROI. In: HINTERHUBER, A.; LIOZU, S. (eds.). Innovation in pricing: contemporary theories and best practices. New York: Routledge, 2013. chapter, 6, p. 119-127.

URDAN, A. T.; OSAKU, W. Determinantes do sucesso de novos produtos: um estudo de empresas estrangeiras no Brasil. In: XXIX ENANPAD - Encontro da Associação Nacional de Pós-Graduação e Pesquisa em Administração. Anais... Brasília: ANPAD, 2005.

WEIJTERS, B.; CABOOTER, E.; SCHILLEWAERT, N. The effect of rating scale format on response styles: the number of responses categories and response category labels.

International Journal of Research in Marketing, v. 27, n. 3, p. 236-247, 2010.

APÊNDICE A - Variáveis (ou Questões) Consideradas na Pesquisa

Processo de Definição de Preços: V01: As vantagens que o produto oferece ao cliente; V02: O equilíbrio entre as REAd | Porto Alegre - Edição 84 - N 2 - Maio / Agosto 2016 - p. 419 - 452 
vantagens do produto e o possível preço; V03: As vantagens que o produto oferece em comparação aos produtos dos concorrentes; V04: O valor percebido do produto pelos clientes (benefícios versus custos); V05: O preço dos produtos dos concorrentes; V06: O grau de competição no mercado; V07: Os sistemas de vendas, divulgação e distribuição dos concorrentes; V08: A atual estratégia de preço dos concorrentes; V09: As reações dos concorrentes aos preços da nossa empresa; V10: As vantagens competitivas dos concorrentes no mercado; V11: O custo total do produto; V12: Os custos variáveis do produto; V13: A margem percentual de lucro definida pela empresa em relação ao preço do produto; V14: O volume de faturamento (receitas) necessário para que se atinja o ponto de equilíbrio e V15: Os investimentos em um novo produto. Desempenho de Novos Produtos: V16: O produto ofereceu qualidade superior (maior) em relação aos concorrentes; V17: O produto solucionou problemas que os clientes tinham com produtos concorrentes e V18: O produto foi bastante inovador e serviu como substituto a outros produtos existentes. Estratégias de Precificação: V19: Definimos o preço inicialmente alto e então, sistematicamente, o reduzimos o tempo; V20: Nossos clientes esperam que o preço caia com o tempo; V21: Definimos o preço baixo para alavancar o volume de vendas e reduzir custos através da experiência acumulada; V22: Sempre procuramos ter um preço baixo (menor) no mercado em relação aos concorrentes; V23: Oferecemos produtos a um preço maior nos segmentos de mercado mais importantes e a um preço menor, por meio de descontos, em segmentos de mercado menos importantes; V24: Oferecemos descontos de forma sistemática e previsível; V25: Nossos clientes observam os preços de nossos produtos como indicadores de alta qualidade; V26: Para produtos que possuem itens complementares ou opcionais (tais como acessórios, partes, peças e serviços), colocamos uma margem de lucro menor no produto básico (central) e margens de lucros maiores nos itens complementares (preço premium); V27: Nossos preços estão em nível intermediário no mercado em função da qualidade intermediária de nossos produtos, em relação aos concorrentes; V28: Oferecemos produtos a preços competitivos, mas também em uma versão mais simples, com menos características ou opções, se comparadas às outras versões; V29: Nossos preços são baixos no mercado em função da qualidade inferior de nossos produtos, em relação à concorrência e V30: Oferecemos pacotes de produtos (um conjunto de vários produtos) em um preço total que permitem aos clientes boas economias se considerassem os produtos comprados individualmente (separadamente). Objetivos dos Novos Produtos: V31: Objetivos de vendas desde que foi lançado; V32: Objetivos de participação de mercado desde o lançamento e V33: Margens de lucro esperadas desde o lançamento. Desempenho em Comparação aos Principais Concorrentes: V34: Vantagem de custos devido à curva de experiência; V35: Vantagem de custos devido às economias de escala; V36: Participação de mercado (7 indica o líder de mercado); V37: Diferenciação dos produtos, de forma geral; V38: Custos totais; V39: Custos fixos; V40: Número de clientes ativos (considerando últimos 12 meses); V41: Preços dos produtos, de forma geral; V42: Crescimento médio no volume das vendas; V43: Capacidade em detectar mudanças de preços; V44: Margem de contribuição média (receitas menos custos variáveis) na venda dos produtos básicos (ou dos produtos "comercializado", para empresas que não trabalhem também com produtos e/ou serviços complementares); V45: Margem de contribuição média (receitas menos custos variáveis) na venda dos produtos (acessórios, opcionais) e/ou serviços complementares, caso existam; V46: Número de itens de produtos comercializados (em linha); V47: Número médio de anos no mercado dos principais produtos comercializados e V48: Número de lançamentos de novos produtos (considerar últimos dois anos). Desempenho do Principal Mercado de Atuação: V49: Crescimento do mercado como um todo; V50: Competição de preços; V51: Sensibilidade dos clientes às diferenças de preço entre marcas (concorrentes); V52: Sensibilidade da demanda total às mudanças no preço médio; V53: Qualidade dos produtos como um todo (no mercado, empresa e concorrentes); V54: Custos totais do setor como um todo; V55: Custos fixos do setor como um todo; V56: Margem de contribuição (receitas menos custos variáveis) na venda dos produtos do setor como um todo; V57: Rentabilidade média do setor como um todo; V58: Barreiras de entrada no mercado aos novos entrantes (concorrentes potenciais); V59: Poder de barganha dos clientes no setor como um todo; V60: Poder de barganha dos fornecedores no setor como um todo e V61: Número de itens de produtos comercializados (em linha) no setor como um todo. Escalas Utilizadas: V01 a V15: 1.Totalmente Desconsiderado a 7.Totalmente Considerado; V16 a V30: 1.Discordo Totalmente a 7.Concordo Totalmente; V31 a V33: 1.Nada Alcançado a 7.Totalmente Alcançado; V34 a V48: 1.Baixo Desempenho a 7.Alto Desempenho e V49 a V61: 1.Baixo(a) a 7.Alto(a). Perfil de Respondentes e Empresas: V62: Cargo ou função desempenhada; V63: Tempo em que trabalhas na empresa; V64: Ramo principal de atuação da empresa; V65: Tempo de atuação de mercado da empresa; V66: Número de clientes ativos (considerar últimos 12 meses); V67: Número de funcionários; V68: Número atual de itens de produtos fabricados e comercializados (em linha); V69: Faturamento anual bruto; V70: Margem líquida de lucro (após imposto de renda e contribuição social); V71: Tempo médio no mercado dos cinco principais produtos (itens) comercializados pela empresa; V72: Número de lançamentos de novos produtos (itens) nos últimos dois anos; V73: A empresa exporta? e V74: A empresa importa? 